\title{
TENTATIVAS DE TRATAMENTO ESPECÍFICO DA FASE AGUDA DA DOENÇA DE CHAGAS COM NITROFURANOS EM ESQUEMAS DE DURAÇÃO PROLONGADA
}

\author{
Anis Rassi * e Humberto de Oliveira Ferreira **
}

Os autores apresentam sua experiência com o emprêgo de nitrofuranos em esquemas de duração prolongada em 37 pacientes na fase agudia da doença de Chagas, parasitolòicamente comprovada através do exame direto.

$A$ atividade terapêtica foi avaliada, fundamentalmente, através do xenodiagnóstico e da reação de Guerreiro e Machado, repetidos o maior número de vêzes possivel ou necessário, cuidando os Autores de não interromper tal prática enquanto resultassem negativos.

Os resultados obtidos demonstraram que os nitrofuranos, especialmente a nitrofurazona e o derivaäo nitrofurfurilidinico "Bayer" 2502, são ativos contra o T. cruzi, exercendo manifesta diminuição da parasitemia, apreciada através do xenodiagnóstico, negativando a reação de Guerreiro e Machado e abreviando o tempo de duração de certas manifestaçóes clinicas. Uma estreita concordância foi notada entre os resultados do xenodiagnóstico e da reação de Guerreiro e Machado, após o tratamento.

$\mathrm{Na}$ maioria dos pacientes pôde ser constatado um efeito supressivo e, em 8 , aparente efeito curativo.

Chamamos a atenção para o cuidado que se deve ter na avaliação dos efeitos terapêuticos e, também, para a necessidade de vigilância médica durante o tratamento, em vista da ocorrência de efeitos colaterais.

Concıuem que, presentemente, em casos agudos, deve ser empregado o derivado nitrofurfurilidinico "Bayer" 2502.

\section{INTRODUÇÃO}

Avaliada através de sua ampla difusão por todo o continente americano, prevalência e patogenicidade, a doença de Chagas representa grave e alarmante problema médico-social, ocupando lugar de grande destaque dentre as endemias rurais.
Num raciocínio simplista e utópico, poder-se-ia considerar a doença de Chagas como problema administrativo, mercê dos eficientes recursos profiláticos de que se dispõe, como a substituição ou melhoria das habitaçōes de precárias condições higiênicas, a desinssetização e a educação sanitária; na prática, entretanto, tais medidas são dificilmente realizáveis na ex-

Chefe do Departamento de Clínica Médica da Faculdade de Medicina da Universidade Federal de Goiás. Professor Adjunto de Cardiologia.

* * Professor Titular de Clinica Pediátrica Médica e Higiene Infantil da Faculdade de Medicina do Triângulo Mineiro.

Recebido para publicação em 27.4.1971. 
tensão necessária, pela complexidade do problema.

A imunização ativa, que tem despertado a atenção de alguns pesquisadores, quiçá represente outro caminho, de perspectivas promissoras, no combate à endemia.

Mesmo conseguida a prevenção efetiva, restariam para tratamento os indivíduos iá infectados, atualmente estimados em 7 milhões.

Por tudo isto, devem ser consideradas válidas quaisquer tentativas de tratamento específico da doença de Chagas, desde que obedecidos os limites da ética e da razão.

Um grande número de medicamentos já foi ensaiado, in vitro e in vivo, experimentalmente e no homem (bibliografia in Brener (5). A maior parte dos mesmos se mostrou totalmente ineficaz, porém, alguns, como derivados quinoleinicos, arsenobenzóis sulfurados, derivados fenantridininicos, compostos nitrofurânicos e antagonistas purinicos evidenciaram nitida atividade tripanosomicida, em maior ou menor grau, ocasionando manifesta diminuição da parasitemia, encurtamento do tempo de duração da fase aguda e diminuição do indice de mortalidade dos animais inoculados. Entretanto, terminado o tratamento, geralmente não eram assinalados resultados animadores, pelo menos nas observaçōes bem conduzidas, dada a persistência da infecção. Cumpre assinalar que, na grande maioria dessas investigaçōes, o tempo de duração do tratamento hoje se nos afigura como absolutamente irrisório, freqüentemente não ultrapassando mais que alguns dias.

Valendo-se da existência de medicamentos com atividade tripanosomicida e da presença de uma fase sanguínea $\mathrm{n}_{0}$ ciclo do T. cruzi, Brener (6) propôs o emprêgo dos mesmos em esquemas de duração prolongada, pois tais condições possibilitariam, teòricamente, a erradicação da infecção; a manutenção de um nível sangüineo ativo da droga por tempo suficientemente longo poderia levar à exaustão parasitária, em virtude da destruição contínua das formas circulantes. Contornarse-ia, assim, o conhecido óbice ao tratamento, representado pela ineficácia dos diversos medicamentos sôbre as formas tissulares. Não esqueceu, o Autor, de citar a possibilidade, não cabalmente comprovada, de que tripanosomas oriundos dos tecidos
F.ossam penetrar, por contigüidade, em novas células, sem cumprir um ciclo sangüineo.

A fim de testar a hipótese, Brener (6) se valeu da nitrofurazona, que, como demonstrou Packhanian (31), apresenta evidente atividade supressiva, destruindo as formas circulantes. Administrou o medicamento, por via oral, a 65 camundongos, durante 53 dias consecutivos, na dose de $100 \mathrm{mg} / \mathrm{kg}$ de pêso/dia, a partir do $4 .^{\circ}$ dia de infecção e pôde observar persistência da infecção em apenas 3 , tendo usado rigorosos métodos de contrôle. Em contrapartida, dentre 10 camundongos tratados com a mesma posologia, durante apenas 20 dias, constatou persistência da infecção em 8.

Face a êsses dados, foram realizadas investigações, usando-se alguns derivados nitrofurânicos, em esquemas de duração prolongada, tanto em infecções experimentais $(4,7,14$ e 42$)$, como humanas $(3,9,10,11$, $12,13,15,17,18,19,21,22,24,28,29,30$, $32,33,37,39,40,41,43$ e 44$)$. A análise dêstes trabalhos permite concluir que, de uma maneira geral, foram obtidos resultados animadores, principalmente com a nitrofurazona e com um derivado nitrofurfurilidínico (Bayer" 2502), dada a significativa atividade dos mesmos, fàcilmente comprovada na fase aguda da infecção; também, que a toxicidade dos nitrofuranos, mais frequiente e mais intersa nos adultos, representa, muitas vêzes, sério óbice a.o tratamento, ocasionando sua suspensão.

Convém salientar que, posteriormente àquela hipótese de Brener, foi constatado, através de investigações experimentais em camundongo, que certos compostos, como a nitrofurazona e o derivado nitrofurfurilidínico "Bayer" 2502, também são ativos sôbre as formas em leishmânia, promovendo a destruição das mesmas, à semelhança do que ocorre com seu emprêgo em culturas de tecidos $(2,4$ e 8$)$.

Desde 1961 vimos nos dedicando às tentativas de tratamento especifico da fase aguda da doença de Chagas com nitrofuranos em esquemas de duração prolongada. Empregamos, inicialmente, a nitrofurazona e, em seguida, por ordem cronológica, a levo-furaltadiona, o hidrocl. de levo-furaltadona, a furazolidona e um derivado nitrofurfurilidínico ("Bayer" 2502), integran- 
do um Grupo de Estudo para o tratamento da doença de Chagas, formado em março de 1962 (24).

\section{MATERIAL E MÉTODOS}

Casuistica. Considerando o achado do Trypanosoma cruzi no sangue periférico, ao exame direto, como sêlo diagnóstico da fase aguda da doença de Chagas, incluímos na presente investigação sòmente casos que preenchessem tal condição.

Nossa casuística é composta de 37 pacientes, 23 do sexo feminino e 14 do masculino, com idade compreendida entre $2 \frac{1}{2}$ meses e 53 anos e com tempo de doença variando entre 3 e 45 dias por ocasião do início do tratamento (Quadro I).

Parte do material foi observado na Clínica Pediátrica Médica e Higiene Infantil da Faculdade de Medicina do Triângulo Mineiro (Uberaba) e parte no Departamento de Clínica Médica da Faculdade de Medicina da Universidade Federal de Goiás (Goiânia)

Aspectos parciais de alguns casos foram apresentados em trabalhos anteriores (19, $21,22,23,24$ e 33) .

Em uma paciente (caso 36) a transmissão da doença se deu, seguramente, através de transfusão de sangue (exsangüíneotransfusão), e em outra (caso 35), apresentando anemia de células falciformes, muito provàvelmente por meio dêste mecanismo. Nos demais, o mecanismo de transmissão foi o habitual.

Estiveram presentes, em tados os casos, as clássicas manifestações clínicas da fase aguda, variáveis em frequiência e intensidade (Quadro II).

Trinta pacientes permaneceram internados durante o tratamento e por algumas semanas ou meses após o mesmo, e 7 (casos 15, 16, 17, 18, 26, 29 e 30) fizeram uso da medicação em domicílio. Todos, ao retornarem às suas residências, receberam noções de profilaxia da doença, principalmente com respeito à desinssetização com vistas à possível reinfecção.

Esquemas terapêticos. Conforme se pode observar nos Quadros III, IV, V, VI e VII, 6 pacientes foram tratados com nitrofurazona "Eaton", 4 com levo-furaltadona (NF-602 "Eaton"), um com hidroclor. de levo-furaltadona (NF-902 "Eaton"), 7 com furazolidona (Furoxona "Eaton"), 6 com associação de 2 dos nitrofuranos aci- ma, um dos quais recebeu, também, primaquina e 13 com um derivado nitrofurfurilidínico ("Bayer" 2502).

A duração do tratamento variou de um mínimo de 39 a um máximo de 153 dias, na dependência da tolerância e em função de observações experimentais.

Em alguns pacientes (cascs 7, 20, $22 \mathrm{e}$ 24) houve deliberada soluçăo de continuidade na administração co medicamento, com vistas à possivel anulação de seus efeitos tóxicos; os demais o usaram contìnuamente.

Com raras exceções, o tratamento foi iniciado tão pronto se efetivasse o diagnóstico parasitológico, através do encontro do $T$. cruzi no sangue periférico, ao exame direto.

$\mathrm{Na}$ grande maioria dos casos empregamos $30 \mathrm{mg} /$ quilo de pêso corporal/dia como posologia máxima e 10 como mínima, por via oral, em doses fracionadas (de 6 em 6 ou de 8 em 8 horas), após refeição; em geral, a dose máxima foi usada apenas nas primeiras semanas de tratamento.

Durante o tratamento, alguns pacientes, sempre que necessário, receberam também medicação para o contrôle de intolerância digestiva, vitaminas $\mathbf{B} 1, \mathbf{B} 6$ e $\mathbf{B} 12$, com vistas às manifestaçōes de polineuropatia, soníferos e orexígenos.

Contrôle da atividade terapêtica. A atividade terapêutica foi avaliada, fundamentalmente, através do xenodiagnóstico (de valor absoluto, pois visa à demonstração do parasito e é altamente sensivel no periodo inicial da infecção), bem como através da reação de Guerreiro e Machado pelo método quantitativo. Valor relativo conferimos às eventuais mudanças dos quadros clínico, eletrocardiográfico, radiológico do coração e laboratorial inespecífico na apreciação dos efeitos terapêuticos.

O critério clínico na apreciação de um ensaio terapêutico tem valor limitado, pelas múltiplas implicações que encerra. Acresce dizer que na fase aguda da doença de Chagas deve-se considerar que a freoüência, a intensidade, o comportamento evolutivo e o tempo de duração das manifestações clínicas muitas vêzes variam bastante de um para outro caso; salientamos, ainda, ser regra o desaparecimento espontâneo das mesmas, umas, ao fim de algumas semanas, e outras, ao fim de alguns meses ( 1 e 34 ). No próprio material 


\section{QUADRO I}

RELAÇÃO DE 37 PACIENTES COM A FASE AGUDA DA DOENÇA DE CHAGAS, PARASITOLÒGICAMENTE COMPROVADA ATRAVÉS DO EXAME DIRETO, TRATADOS COM NITROFURANOS EM ESQUEMAS DE DURAÇĂO PROLONGADA

\begin{tabular}{|c|c|c|c|c|c|c|}
\hline Caso & Iniciais & Sexo & Côr & Idade & $\begin{array}{l}\text { Pêso } \\
\text { (kg) }\end{array}$ & $\begin{array}{c}\text { Tempo de } \\
\text { doença } \\
\text { (em dias) }\end{array}$ \\
\hline $\begin{array}{r}1 \\
2 \\
3 \\
4 \\
5 \\
6 \\
7 \\
8 \\
9 \\
10 \\
11 \\
12 \\
13 \\
14 \\
15 \\
16 \\
17 \\
18 \\
19 \\
20 \\
21 \\
22 \\
23 \\
24 \\
25 \\
26 \\
27 \\
28 \\
29 \\
30 \\
31 \\
32 \\
33 \\
34 \\
35 \\
36 \\
37\end{array}$ & $\begin{array}{l}\text { J. D. G. } \\
\text { M. M. G. } \\
\text { S. H. S. } \\
\text { J. B. P. } \\
\text { C. M. C. } \\
\text { B. P. M. } \\
\text { M. H. F. } \\
\text { S. M. C. } \\
\text { S. S. G. F. } \\
\text { M. S. G. F. } \\
\text { G. L. M. } \\
\text { C. C. S. } \\
\text { A. D. O. } \\
\text { P. J. O. } \\
\text { E. M. A. } \\
\text { V. A. } \\
\text { I. B. B. } \\
\text { E. S. } \\
\text { N. L. S. } \\
\text { M. S. } \\
\text { O. A. L. S. } \\
\text { S. M. R. } \\
\text { J. E. S. M. } \\
\text { N. T. O. } \\
\text { M. G. O. } \\
\text { W. S. O. } \\
\text { L. A. B. } \\
\text { M. N. S. } \\
\text { J. A. R. S. } \\
\text { R. R. S. } \\
\text { J. G. A. } \\
\text { R. C. } \\
\text { I. M. J. } \\
\text { M. A. G. G. } \\
\text { A. G. R. C. } \\
\text { M. A. L. }\end{array}$ & 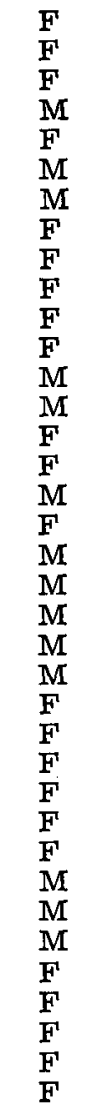 & $\begin{array}{l}\mathrm{Pd} \\
\mathrm{Pd} \\
\mathrm{Pd} \\
\mathrm{B} \\
\mathrm{B} \\
\mathrm{Pt} \\
\mathrm{Pd} \\
\mathrm{B} \\
\mathrm{B} \\
\mathrm{Pd} \\
\mathrm{B} \\
\mathrm{Pd} \\
\mathrm{B} \\
\mathrm{B} \\
\mathrm{B} \\
\mathrm{B} \\
\mathrm{B} \\
\mathrm{B} \\
\mathrm{Pt} \\
\mathrm{Pd} \\
\mathrm{Pd} \\
\mathrm{B} \\
\mathrm{B} \\
\mathrm{B} \\
\mathrm{B} \\
\mathrm{B} \\
\mathrm{B} \\
\mathrm{Pd} \\
\mathrm{B} \\
\mathrm{B} \\
\mathrm{Pd} \\
\mathrm{B} \\
\mathrm{Pd} \\
\mathrm{B} \\
\mathrm{B} \\
\mathrm{B} \\
\mathrm{B}\end{array}$ & $\begin{array}{rl}5 & \mathrm{a} \\
7 & \mathrm{a} \\
6 \mathrm{a} \\
3 \mathrm{~m} \\
16 \mathrm{a} \\
13 \mathrm{a} \\
10 \mathrm{a} \\
8 \mathrm{a} \\
9 \mathrm{a} \\
13 \mathrm{a} \\
11 \mathrm{a} \\
2 \mathrm{a} \\
39 \mathrm{a} \\
5 \mathrm{a} \\
48 \mathrm{a} \\
29 \mathrm{a} \\
24 \mathrm{a} \\
12 \mathrm{a} \\
18 \mathrm{a} \\
6 \mathrm{a} \\
10 \mathrm{a} \\
10 \mathrm{a} \\
5 \mathrm{a} \\
2 \mathrm{a} \\
11 \mathrm{a} \\
16 \mathrm{a} \\
5 \mathrm{a} \\
9 \mathrm{a} \\
6 \mathrm{~m} \\
53 \mathrm{a} \\
7 \mathrm{a} \\
7 \mathrm{a} \\
6 \mathrm{a} \\
10 \mathrm{a} \\
9 \mathrm{a} \\
2,5 \mathrm{~m} \\
13 \mathrm{a}\end{array}$ & $\begin{array}{r}15,0 \\
17,0 \\
16,4 \\
6,1 \\
46,2 \\
29,5 \\
30,0 \\
24,0 \\
5,8 \\
30,0 \\
36,5 \\
11,5 \\
60,8 \\
11,7 \\
40,0 \\
48,7 \\
60,0 \\
30,0 \\
49,0 \\
20,0 \\
24,0 \\
34,8 \\
16,5 \\
9,5 \\
31,0 \\
45,0 \\
18,5 \\
28,3 \\
6,4 \\
50,0 \\
24,0 \\
19,0 \\
15,5 \\
34,0 \\
19,6 \\
5,0 \\
40,0\end{array}$ & $\begin{array}{r}15 \\
15 \\
12 \\
10 \\
43 \\
27 \\
15 \\
18 \\
9 \\
24 \\
7 \\
27 \\
19 \\
3 \\
21 \\
21 \\
8 \\
19 \\
21 \\
15 \\
22 \\
18 \\
31 \\
13 \\
15 \\
31 \\
19 \\
21 \\
20 \\
25 \\
16 \\
31 \\
11 \\
37 \\
23 \\
45 \\
20\end{array}$ \\
\hline
\end{tabular}

* Por ocasião do início do tratamento. 
QUADRO II

MANIFESTAÇÕES CLINICAS APRESENTADAS POR 37 PACIENTES COM A FASE AGUDA DA DOENCGA DE CHAGAS, PARASITOLÒGICAMENTE COMPROVADA ATRAVÉS DO EXAME DIRETO, TRATADOS COM NITROFURANOS EM ESQUEMAS DE DURAÇÃO PROLONGADA

\begin{tabular}{|c|c|c|c|}
\hline \multicolumn{2}{|r|}{ Manifestações clínicas } & $\begin{array}{l}\text { N. de } \\
\text { casos }\end{array}$ & Relação dos casos \\
\hline 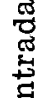 & Sinal de Romaña .. & 16 & $\begin{aligned} 3-4-5-8-9-10-12-14-16-19 & -19-21-23-26-28-32-33 .\end{aligned}$ \\
\hline$\Phi$ & Chagoma & 10 & $1-6-7-11-20-22-25-27-30-34$ \\
\hline$\overbrace{0}^{\pi}$ & Inaparente & 10 & $2-13-15-17-18-24-29-31-35-37$ \\
\hline & Exsanguíneo - transfusão & 1 & 36 \\
\hline & Febre & 37 & Todos os casos \\
\hline 离 & Hipertrofia ganglionar & 17 & $\begin{aligned} 1-2-7-8-9-10-12-16-19-20 & -21-23-25-31-32-34-35 .\end{aligned}$ \\
\hline . & Edema subcutâneo & 17 & $\begin{aligned} 2-5-8-9-12-14-16-21-23-24 & -25-27-29-33-34-35-37 .\end{aligned}$ \\
\hline$\stackrel{\leftrightarrow}{ٌ}$ & Hepatomegalia & 9 & $1-9-10-12-21-33-34-35-36$. \\
\hline$\stackrel{\Xi}{\mathrm{Z}}$ & Esplenomegalia & 6 & $7-10-21-33-34-36$ \\
\hline
\end{tabular}

em estudo constatamos, às vêzes, a remissāo de uma manifestação antes mesmo do início da terapêutica.

Também os aspectos eletrocardiográfico e radiológico do coraçāo têm apenas valor relativo e merecem criteriosa análise na avaliação da atividade medicamentosa porque, na grande maioria dos casos agudos, sem nenhum tratamento, as alterações desaparecem algumas semanas ou meses após sua observação (35) .

Quanto às provas laboratoriais inespecíficas, que poderiam ser tomadas como mensuradoras da atividade do processo, as mesmas críticas devem ser feitas, pois, geralmente se normalizam, ou tendem a normalizar-se, espontâneamente, acompanhando o declínio das demais manifestações.

Tanto o xenodiagnóstico como a reação de Guerreiro e Machado foram repetidos o maior número de vêzes possível ou necessário, durante e após o tratamento, a intervalos dentro do possivel regulares, cuidando-nos de não interromper tal prática enquanto resultassem negativos. Ambos os exames foram realizados no Departamen- to de Parasitologia da Faculdade de Medicina de Ribeirão Prêto. Em cada xenodiagnóstico empregamos 10 triatomíneos, à exceção dos aplicados nos casos 5 e 6 , nos quais um número maior foi utilizado, como se poderá notar ao tratarmos dos resultados. Quanto à reação de Guerreiro e Machado, consideramos como reagente todos os exames com título superior a 1,5, de acôrdo com Freitas \& Almeida (26).

\section{RESULTADOS}

Xenodiagnóstico e reação āe Guerreiro e Machado. Os resultados de xenodiagnóstico e de reações de Guerreiro e Machado, praticados antes, durante e após o tratamento, para avaliação dos efeitos terapêuticos, estão expostos nos Quadros III, IV, V, VI e VII e nos Gráficos I e II. Achamse expressos, nos Quadros, o número de exames realizados em cada caso, bem como, entre parêntesis, o período de tempo, após o tratamento, durante o qual foram executados. Eventualmente, um ou outro triatomíneo de cada xenodiagnóstico não foi examinado, por se apresentar morto e sêco. 
QUADRO V

RESULTADOS OBTIDOS EM 7 PACIENTES TRATADOS COM FURAZOLIDONA (FUROXONA 'EATON"), POR VIA ORAL, NA FASE AGUDA DA DOENÇA DE CHAGAS

Em todos os casos a pesquisa de $T$. cruzi no sangue periférico, ao exame direto, antes do tratamento, resultou positiva

\begin{tabular}{|c|c|c|c|c|c|c|c|c|c|c|}
\hline \multirow{3}{*}{ Cass } & \multicolumn{3}{|c|}{ ESQUEMA TERAPEUUTICO } & \multirow{2}{*}{\multicolumn{3}{|c|}{$\frac{\text { CONTRÔLE DA }}{\text { (10 triatomíneos em cada exame })}$}} & \multicolumn{2}{|c|}{ ATIVIDADE } & \multicolumn{2}{|c|}{ TERAPEUTICA } \\
\hline & \multirow{2}{*}{$\underset{(\mathrm{mg} / \mathrm{kg} /}{\text { Dose }}$} & \multirow{2}{*}{ N..$^{\circ}$ de dias } & \multirow{2}{*}{$\begin{array}{c}\text { Duração } \\
\text { total } \\
\text { (em dias) }\end{array}$} & & & & $\begin{array}{l}\text { XENODIAGNósTICOS } \\
\text { (10 triatomíneos em cada exame) }\end{array}$ & \multicolumn{3}{|c|}{$\begin{array}{c}\text { REAÇOEES DE GUERREIRO e MACHADO } \\
\text { (método quantitativo) }\end{array}$} \\
\hline & & & & Antes & Durante & Após & & Antes & Durante & Após \\
\hline 12 & 30 & 45 & 45 & $2 \mathrm{P}$ & $\cdots$ & 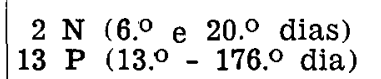 & & $1 \mathrm{R}$ & $1 \mathrm{R}$ & $4 \mathrm{R}$ (11. $.^{\circ} \mathrm{dia}-2 .^{\circ}$ ano $)$ \\
\hline 13 & $\begin{array}{l}30 \\
15\end{array}$ & $\begin{array}{r}17 \\
136\end{array}$ & 153 & $1 \mathrm{P}$ & $\ldots$ & $\begin{array}{l}6 \mathrm{~N}\left(1.0^{\circ}-410^{\circ} \mathrm{dia}\right) \\
3 \mathrm{P}\left(480^{\circ}-62 .^{\circ} \mathrm{dia}\right)\end{array}$ & & $1 \mathrm{R}$ & $4 \mathrm{R}$ & $3 R\left(26 .^{\circ}-99 .^{\circ}\right.$ dia $)$ \\
\hline 14 & $\begin{array}{l}30 \\
10\end{array}$ & $\begin{array}{l}15 \\
35\end{array}$ & 50 & $\ldots$ & $1 \mathrm{~N}$ & $5 \mathrm{~N}\left(11 .^{\circ}-281 .^{\circ} \mathrm{dia}\right)$ & & & $1 \mathrm{~N}$ & $7 \mathrm{~N}$ (11..$^{\circ}$ dia $-5 .^{\circ}$ ano $)$ \\
\hline 15 & 10 & 60 & 60 & . . & $1 \mathrm{P}$ & $\begin{array}{l}2 \mathrm{~N}\left(14 .^{\circ} \mathrm{e} 75 .^{\circ} \text { dias }\right) \\
1 \mathrm{P}\left(126 .^{\circ} \text { dia }\right)\end{array}$ & & $\ldots$ & $\ldots$ & $\begin{array}{l}1 \mathrm{~N}\left(1260^{\circ} \mathrm{dia}\right) \\
3 \mathrm{R}\left(14 .^{\circ}-338 .^{\circ} \text { dia }\right)\end{array}$ \\
\hline 16 & 10 & 60 & 60 & $\ldots$ & $2 \mathrm{~N}$ & $1 P\left(17 .^{\circ}\right.$ dia $)$ & & $1 \mathrm{R}$ & & $1 \mathrm{R}\left(47 .^{\circ} \mathrm{dia}\right)$ \\
\hline 17 & 10 & 60 & 60 & $\cdots$ & $\ldots$ & $1 P(31.0$ dia $)$ & & $1 \mathrm{R}$ & $2 \mathrm{R}$ & $2 R\left(31 .^{\circ}\right.$ e $1160^{\circ}$ dias $)$ \\
\hline 18 & 10 & 60 & 60 & $\ldots$ & $\ldots$ & $1 P(20.0$ dia $)$ & & $1 \mathrm{R}$ & $\cdots$ & $\begin{array}{l}1 \mathrm{~N}\left(20.0^{\circ} \text { dia }\right) \\
1 \mathrm{R}\left(46 .{ }^{\circ} \text { dia }\right) \\
\end{array}$ \\
\hline \multicolumn{4}{|c|}{$\begin{array}{l}\text { \% de xenodiagnósticos positivos e de rea- } \\
\text { ções de Guerreiro e Machado reagentes }\end{array}$} & 100 & 33,3 & $\begin{array}{ll}\text { A } & \text { curto prazo } \\
\text { A } & \text { longo } \\
\text { prazo } & \ldots\end{array}$ & $\begin{array}{l}57,1 \\
85,7\end{array}$ & 100 & 75,0 & $\begin{array}{llll}\text { A curto prazo } & \ldots & 57,1 \\
\text { A longo prazo } & \ldots & 85,7\end{array}$ \\
\hline
\end{tabular}

$\mathrm{P}$ significa positivo, $\mathrm{R}$ reagente, $\mathbf{N}$ negativo e ... dado ignorado. Os algarismos antes dessas letras correspondem ao número de exames realizados. Entre parêntesis, acha-se assinalado o período de tempo, após o tratamento, durante o qual fọram praticados os exames. 
QUADRO VI

RESULTADOS OBTIDOS EM 6 PACIENTES TRATADOS COM ASSOCIAÇÃO DE NITROFURANOS, POR VIA ORAL, NA FASE AGUDA DA DOENÇA DE CHAGAS

Em todos os casos a pesquisa de $T$. cruzi no sangue periférico, ao exame direto, antes do tratamento, resultou positiva

\begin{tabular}{|c|c|c|c|c|c|c|c|c|c|c|}
\hline \multirow{3}{*}{ Caso } & \multirow{3}{*}{ Medicamentos } & \multicolumn{3}{|c|}{$\begin{array}{c}\text { ESQUEMA } \\
\text { TERAPEUTICO }\end{array}$} & \multicolumn{6}{|c|}{ CONTRÔLE DA ATIVIDADE TERAPÊUTICA } \\
\hline & & \multirow{2}{*}{$\begin{array}{l}\text { Dose } \\
\text { (mg/kg/ }\end{array}$} & \multirow{2}{*}{$\begin{array}{l}\text { N.o de } \\
\text { dias }\end{array}$} & \multirow{2}{*}{$\begin{array}{c}\text { Duração } \\
\text { total(em } \\
\text { dias) }\end{array}$} & \multicolumn{3}{|c|}{$\begin{array}{l}\text { XENODIAGNÓSTICOS } \\
\text { (10 triatomíneos em cada exame) }\end{array}$} & \multicolumn{3}{|c|}{$\begin{array}{l}\text { REAÇÕES DE GUERREIRO E MACHADO } \\
\text { (método quantitativo) }\end{array}$} \\
\hline & & & & & Antes & Durante & Após & Antes & Durante & Após \\
\hline 19 & $\begin{array}{l}\text { Nitrofurazona } \ldots \\
\text { Furazolidona } \ldots\end{array}$ & $\begin{array}{l}30 \\
10\end{array}$ & $\begin{array}{l}15 \\
35\end{array}$ & 50 & $\cdots$ & $4 N$ & $18 \mathrm{~N}\left(41 .^{\circ}\right.$ dia $\left.-3 .^{\circ} \mathrm{ano}\right)$ & $\cdots$ & $1 \mathrm{R}$ & $17 \mathrm{~N}\left(60 .^{\circ} \mathrm{dia}-3 .^{\circ}\right.$ ano $)$ \\
\hline 20 & $\begin{array}{ll}\text { Nitrofurazona } & \ldots \\
\text { L-Furaltadona } & \ldots\end{array}$ & $\begin{array}{l}40 \\
30\end{array}$ & $\begin{array}{l}10 \\
36(a)\end{array}$ & 46 & $1 \mathrm{P}$ & $4 \mathrm{~N}$ & $1 P\left(25 .^{\circ}\right.$ dia $)$ & $1 \mathrm{R}$ & $3 \mathrm{~N}$ & $1 \mathrm{R}\left(250^{\circ} \mathrm{dia}\right)$ \\
\hline 21 & $\begin{array}{l}\text { Nitrofurazona } \ldots \\
\text { L-Furaltadona } \\
\text { L-Furaltadona }\end{array}$ & $\begin{array}{l}30 \\
30 \\
10\end{array}$ & $\begin{array}{l}13 \\
16 \\
97\end{array}$ & 126 & $1 \mathbf{P}$ & $\cdots$ & $\begin{array}{l}2 \mathrm{~N}\left(10^{\circ} \text { e } 80^{\circ} \text { dias }\right) \\
6 \mathrm{P}\left(200^{\circ}-64 .^{\circ} \text { dia }\right)\end{array}$ & $1 \mathrm{R}$ & $5 \mathrm{R}$ & $2 R\left(23 .^{\circ}\right.$ e $51 .^{\circ}$ dias $)$ \\
\hline 22 & $\begin{array}{l}\text { Nitrofurazona }+ \\
+ \text { Primaquina } \\
\text { L-Furaltadona }\end{array}$ & $\begin{array}{l}30 \\
0,43 \\
10\end{array}$ & $\begin{array}{l}30 \\
30 \\
60\end{array}$ & 120 & $1 \mathbf{P}$ & $\cdots$ & $\begin{array}{l}9 \mathrm{~N}\left(13 .^{\circ}-1480^{\circ} \mathrm{dia}\right) \\
2 \mathrm{P}\left(60^{\circ} \text { e } 63 .^{\circ} \text { dias }\right)\end{array}$ & $1 \mathrm{~N}$ & $3 \mathrm{R}$ & $\begin{array}{l}1 \mathrm{~N}\left(9 .^{\circ} \text { dia }\right) \\
2 \mathrm{R}\left(148 .^{\circ} \text { e } 359 .^{\circ} \text { dias }\right)\end{array}$ \\
\hline 23 & $\begin{array}{l}\text { Hidrocl. de } \\
\text { L-Furaltadona (c). } \\
\text { L-Furaltadona .... }\end{array}$ & $\begin{array}{l}30 \\
10\end{array}$ & $\begin{array}{l}15 \\
35\end{array}$ & 50 & & $3 \mathrm{~N}$ & $\begin{array}{l}6 \mathrm{~N}\left(100^{\circ}-196 .^{\circ} \mathrm{dia}\right) \\
1 \mathrm{P}\left(304 .^{\circ} \mathrm{dia}\right)\end{array}$ & $1 \mathrm{R}$ & $\cdots$ & $\begin{array}{l}6 \mathrm{~N}\left(100^{\circ}-196 .^{\circ} \mathrm{dia}\right) \\
1 \mathrm{R}\left(304 .^{\circ} \mathrm{dia}\right)\end{array}$ \\
\hline 24 & $\begin{array}{l}\text { Hidrocl. de } \\
\text { L-Furaltadona .... } \\
\text { Furazolidona }(\mathrm{e}) \ldots \\
\text { Furazolidona } \ldots . . .\end{array}$ & $\begin{array}{l}30 \\
20 \\
10\end{array}$ & $\begin{array}{l}30(d) \\
15 \\
35\end{array}$ & 80 & & $1 \mathrm{P}$ & $1 \mathrm{P}\left(12 .^{\circ} \mathrm{dia}\right)$ & $1 \mathrm{R}$ & $4 \mathrm{R}$ & $3 N\left(12 .^{\circ}-236 .^{\circ} \mathrm{dia}\right)$ \\
\hline $\begin{array}{cc}\% & \mathrm{de} \\
& \mathrm{Gu}\end{array}$ & $\begin{array}{l}\text { xenodiagnósticos po } \\
\text { derreiro e Machado }\end{array}$ & $\begin{array}{l}\text { sitivos } \mathrm{e} \\
\text { reagentes }\end{array}$ & $\begin{array}{l}\text { de } \text { reaç } \\
\ldots \ldots\end{array}$ & $\begin{array}{l}\text { ões de } \\
\ldots \ldots\end{array}$ & 100 & 25,0 & $\begin{array}{llll}\text { A curto prazo } & \ldots & 66,6 \\
\text { A longo prazo } & . & 83,3\end{array}$ & 80,0 & 80,0 & $\begin{array}{llll}\text { A curto prazo } & . . & 33,3 \\
\text { A longo prazo } & . & 66,6\end{array}$ \\
\hline
\end{tabular}

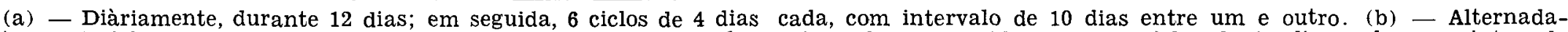

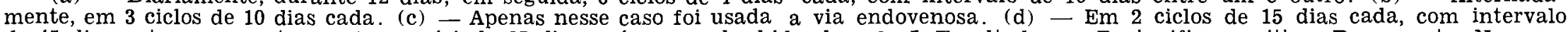

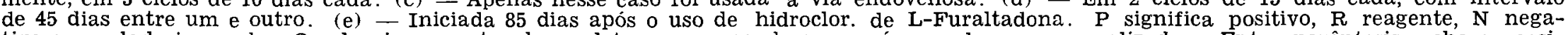

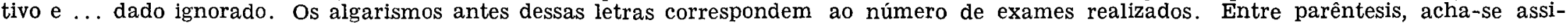
nalado o período de tempo, após o tratamento, durante o qual foram praticados os exames. 


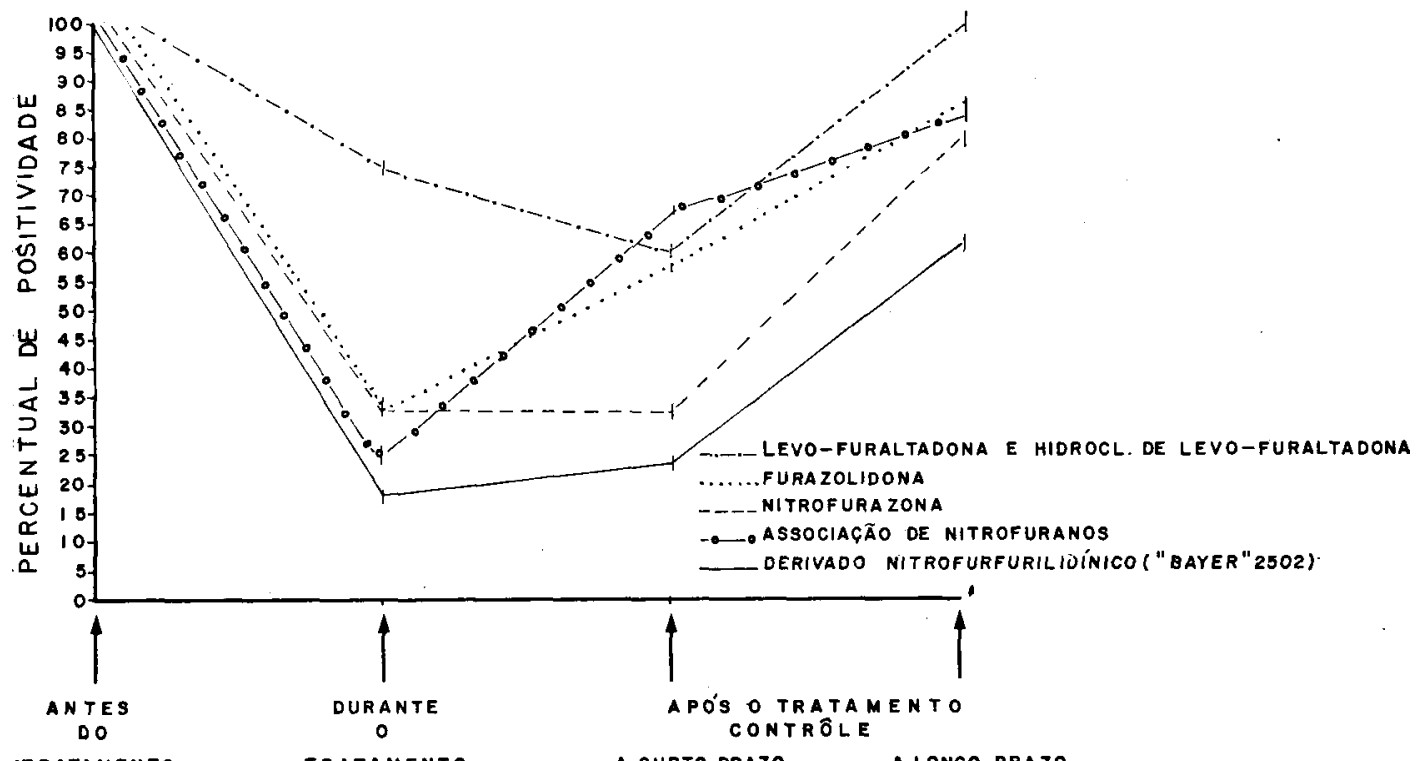

TRATAMENTO

TRATAMENTO

A CURTO PRAZO A LONGO PRAZO

Gráfico I - Evolução do xenodiagnóstico em pacientes com a fase aguda da doença de Chagas, tratados com nitrofuranos em esquemas de duração prolongada. Valores médios obtidos em 37 casos.

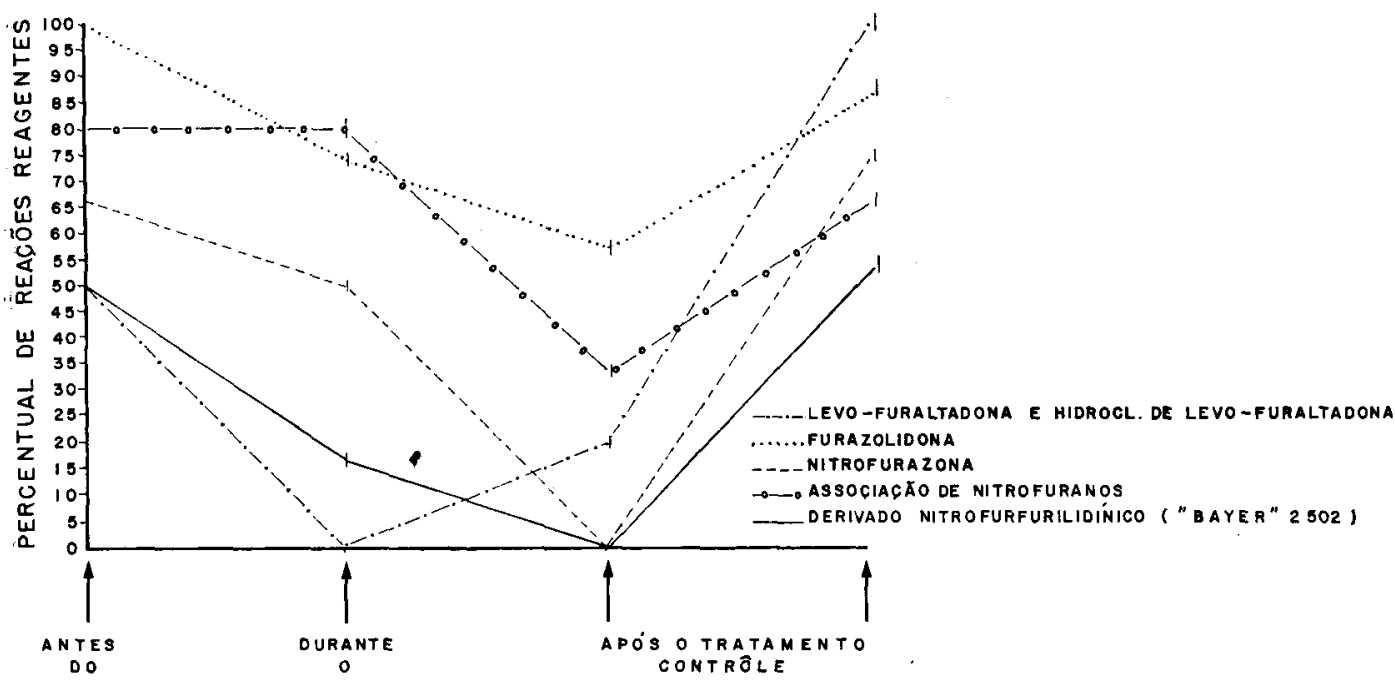

TRATAM ENTO

TRATAMENTO

A cURTo PRAZO A LONGO PRAZO

Gráftco II - Evoluçăo da reação de Guerreiro e Machado em pacientes com a fase aguda da doença de Chagas, tratados com nitrofuranos em esquemas de duração prolongada. Valores médios obtidos em 37 casos. 
Arbitramos como contrôle terapêutico a curto prazo, o realizado em tôrno do primeiro mês após o tratamento, e a longo prazo, o praticado no decorrer dos meses ou anos subseqüentes ao mesmo.

Em alguns casos não estão consignados os resultados dos referidos exames antes ou durante o tratamento, seja pela falta momentânea de triatomíneos, seja porque o sôro sanguíneo se tivesse mostrado anticomplementar.

Antes do tratamento o xenodiagnóstico resultou positivo na totalidade dos casos em que foi realizado. Conquanto se saiba da possibilidade, embora remota, de um xenodiagnóstico eventualmente resultar negativo na fase aguda da doença de Chagas (16 e 36), consideramos a totalidade dos pacientes da série em estudo como apresentando positivo êste exame, extrapolação bastante válida porque, em todos êles o exame direto - método bem menos sensivel que o xenodiagnóstico para detecção do parasito - resultou positivo.

Para o cálculo dos percentuais de positividade do xenodiagnóstico e das reações de Guerreiro e Machado reagentes, durante e após o tratamento, adotamos os seguintes critérios:

1.․ Os casos que apresentaram xenodiagnósticos ora positivos, ora negativos, num mesmo período de contrôle, foram incluídos no grupo dos positivos (caso 8, por exemplo, durante o tratamento e caso 22, após o tratamento, no contrôle a curto prazo).

2.:: Quanto à reação de Guerreiro e Machado, consideramos 0 último resultado de cada período, tendo em vista o prazo necessário para que ocorra o esgotamento de anticorpos (caso 34, por exemplo, após - tratamento, a curto prazo).

3. . Os pacientes que apresentaram exames positivos a curto prazo e não o fizeram a longo prazo, foram considerados como positivos nesse último período. A recíproca nāo foi tomada como verdadeira e, nessa situação, os percentuais foram calculados com a exclusão dêsses casos.

No Quadro III, que relaciona os 6 casos que receberam nitrofurazona "Eaton", observa-se que, após o tratamento, no contrôle a curto prazo, apenas $33,3 \%$ dos pacientes continuaram com xenodiagnóstico positivo e que a reação de Guerreiro e $\mathrm{Ma}$ chado resultou negativa em todos êles; a análise a longo prazo, entretanto, mostra elevação do percentual de positividade do xenodiagnóstico $(80,0 \%)$ e que $75,0 \%$ dos pacientes passaram a apresentar reação de Guerreiro e Machado reagente.

O caso 1 , durante o tratamento, teve 3 xenodiagnósticos negativos (praticados no $18 .^{\circ}, 33 .^{\circ}$ e $46 .^{\circ}$ dias) e uma reação de Guerreiro e Machado positiva (realizada no $36 .^{\circ}$ dia); após o tratamento, apresentou xenodiagnósticos e reações de Guerreiro e Machado reiteradamente negativos; em seu contrôle, já no $70^{\circ}$ ano após o tratamento, resultaram negativos 30 xenodiagnósticos e 29 reações de Guerreiro e Machado, simultâneamente praticados.

Nos casos 5 e 6 o contrôle parasitológico foi feito diferentemente de todos os demais, conforme ressaltamos anteriormente. No caso 5 , entre o $6 .^{\circ}$ e o $100^{\circ}$ dias após o tratamento, foram realizados xenodiagnósticos em 4 dias diferentes, sendo alicados 111 triatomíneos, dos quais 107 se mostraram negativos e 4 mortos e secos; entre o $700^{\circ}$ e $81 .^{\circ}$ dias foram aplicados, nesse caso, em 7 dias diferentes, mais 200 triatomíneos, dos quais 116 resultaram negativos, 75 positivos e 9 se apresentaram mortos e secos; a reação de Guerreiro e Machado mostrou-se reagente nos primeiros dias após o tratamento, tornou-se negativa em seguida e, finalmente, voltou a ser reagente. No caso 6 foram praticados xenodiagnósticos diàriamente, nos 4 primeiros dias após o tratamento, sendo usado um total de 157 triatomíneos, dos quais 133 resultaram negativos, 17 positivos e 7 mortos e secos; a reação de Guerreiro e Machado, após o tratamento, teve comportamento idêntico ao do caso 5 .

No Quadro IV estão expostos os resultados de 4 pacientes tratados com levofuraltadona "Eaton" (NF - 602) e de um medicado com hidrocl. de levo-furaltadona "Eaton" (NF - 902). Após o tratamento, no contrôle a curto prazo, $60,0 \%$ dos mesmos tiveram xenodiagnósticos positivos e apenas $20,0 \%$ apresentaram reação de Guerreiro e Machado reagente; já a longo prazo, na totalidade dos casos, ambos os exames resultaram positivos. Apenas uma paciente (caso 10) teve xenodiagnósticos negativos em número significativo (treze), até o $1100^{\circ}$ dia após o tratamento, com negatividade temporária da reação de Guerreiro e Machado. 


\section{Q U A D R O VIII}

RESULTADOS DE ELETROCARDIOGRAMAS PRATICADOS ANTES E APÓS O TRATAMENTO EM 24 PACIENTES COM A FASE AGUDA DA DOENÇA DE CHAGAS, PARASITOLÖGICAMENTE COMPROVADA ATRAVÉS DO EXAME DIRETO, TRATADOS COM NITROFURANOS EM ESQUEMAS DE DURAÇÃO PROLONGADA

\begin{tabular}{|c|c|c|c|c|c|c|}
\hline \multirow[b]{2}{*}{ RESULTADO * } & \multicolumn{3}{|c|}{ ANTES DO TRATAMENTO } & \multicolumn{3}{|c|}{ APÓS O TRATAMENTO } \\
\hline & $\begin{array}{l}\text { N. }{ }^{\circ} \text { de } \\
\text { casos }\end{array}$ & Relação dos casos & $\%$ & $\begin{array}{l}\text { N.o de } \\
\text { casos }\end{array}$ & Relação dos casos & $\%$ \\
\hline Normal .. . & 7 & $1-10-11-13-24-29-34$ & 29,1 & 22 & $\left|\begin{array}{r}1-3-5-6-7-10-11-12-13 \\
-19-21-22-24-25-27- \\
28-30-31-33-34-36-37\end{array}\right|$ & 91,6 \\
\hline 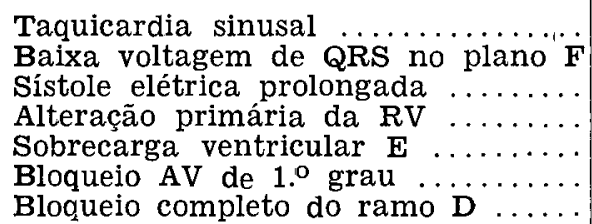 & $\begin{array}{l}8 \\
3 \\
6 \\
6 \\
2 \\
2 \\
1\end{array}$ & $\begin{array}{l}12-22-27-30-31-33-36-37 \\
6-21-27 \\
3-7-27-31-33-37 \\
5-6-12-25-28-37 \\
35 * *-36 \\
25-36 \\
19\end{array}$ & $\begin{array}{r}33,3 \\
12,5 \\
25,0 \\
25,0 \\
8,3 \\
8,3 \\
4,1\end{array}$ & $\begin{array}{l}\frac{-}{1} \\
\frac{1}{1} \\
-\end{array}$ & $\begin{array}{l}-20-00-01-00-04-00-00 \\
\frac{29}{35^{* *}} \\
-\end{array}$ & $\begin{array}{l}\overline{\overline{4}} \\
\overline{4,1} \\
\overline{4}\end{array}$ \\
\hline
\end{tabular}

* Às vêzes, duas ou mais alterações estiveram presentes num mesmo paciente.

** Paciente com anemia de célułas falciformes. 
No Quadro V, que exibe os resultados de 7 pacientes submetidos a tratamento com furazolidona (Furoxona "Eaton"), constata-se que, na avaliação a curto prazo, $57,1 \%$ dos casos mostraram xenodiagnósticos positivos e reações de Guerreiro e Machado reagentes, elevando-se a cifra para $85,7 \%$ na apreciação a longo prazo. Sòmente um paciente (caso 14) continuou com ambos os exames negativos, após o tratamento, enquanto pôde ser realizado o contrôle, num total de 5 xenodiagnósticos (até a $281 .^{\circ}$ dia) e de 7 reações (até o $5^{\circ}$ ano); nesse caso, ambos os exames, durante o tratamento, também resultaram negativos.

No Quadro VI acham-se os resultados de 6 casos medicados com associação de nitrofuranos, num dos quais (caso 22) empregamos também a Primaquina. Nota-se que, a curto prazo, o xenodiagnóstico resultou positivo em $66,6 \%$ dos pacientes $\mathrm{e}$ que reações de Guerreiro e Machado reagentes foram obtidas em $33,3 \%$ dos casos; a longo prazo os referidos exames tiveram valores mais altos $(83,3 \%$ e $66,6 \%$, respectivamente). Num único paciente (caso 19) ambos os exames persistiram negativos (18 xenodiagnósticos e 17 reações de Guerreiro e Machado) até o $3 .^{\circ}$ ano após o tratamento; nesse caso, durante o tratamento, foram obtidos 4 xenodiagnósticos negativos e uma reação positiva.

O Quadro VII mostra os resultados de 13 pacientes que usaram um derivado nitrofurfurilidínico ("Bayer" 2502). Verificase que, antes do tratamento, o xenodiagnóstico resultou positivo na totalidade $(\mathbf{1 0 0 \% )}$ dos casos e a reação de Guerreiro e Machado se mostrou reagente em 53,8\%. Durante o tratamento houve queda dêstes percentuais para $18,1 \%$ e $16,6 \%$, respectivamente; a reação de Guerreiro e Machado tornou-se negativa em 5 casos e, em 5 , continuou negativa, como antes da terapêutica. Após o tratamento, na avaliação a curto prazo, 23,0\% dos pacientes apresentaram xenodiagnósticos positivos e $\mathrm{em}$ nenhum caso $(0,0 \%)$ a reação de Guerreiro e Machado se mostrou positiva; continuou negativa naqueles 10 casos e tornouse negativa nos 3 restantes; nas avaliações a longo prazo, entretanto elevou-se o percentual de positividade do xenodiagnóstico e de reações reagentes para $61,5 \%$ e $\mathbf{5 3 , 8} \%$, respectivamente; apenas $5(38,4 \%)$ dentre os 13 pacientes (casos $25,30,31,32$ e 33) continuaram com ambos os exames negativos, realizados no mínimo 4 vêzes $e$ no máximo 17 , evolutivamente, decorridos vários meses (de sete a vinte e sete) após o tratamento; nos demais, tanto o xenodiagnóstico voltou a ser positivo, como a reação de Guerreiro e Machado reagente, cumprindo observar que, no caso 29 , tanto antes, como durante e após o tratamento, aquêle exame resultou sempre positivo e, êste, sempre negativo.

Quadro clínico. Tendo em conta, as ressalvas assinaladas anteriormente, feitas com o intuito de situar o critério clínico em seu devido lugar, permitimo-nos apreciar o comportamento das manifestações clínicas, durante e após o tratamento, tão sòmente de modo panorâmico, ainda mais porque nossa casuística é relativamente pequena e heterogênea. Com a experiência acumulada pelo estudo de pacientes cuja fase aguda evoluiu espontâneamente (20 e 34), pudemos notar que os nitrofuranos, especialmente a nitrofurazona e o derivado nitrofurfurilidínico ("Bayer" 2502), foram úteis no sentido de abreviar o tempo de duração da sintomatologia clínica, principalmente da febre, do edema e dos sinais de porta de entrada do infecção; quanto à hepatomegalia, esplenomegalia e hipertrofia ganglionar, a regressāo foi mais lenta, às vêzes não diferindo, essencialmente, dos casos deixados evoluir naturalmente.

Estudo eletrocardiográfico e radiológico do coração. Nos Quadros VIII e IX estão consignados os resultados de eletrocardiogramas e de exames radiolózicos do coração antes e após o tratamento, em 24 e em 22 casos, respectivamente.

No Quadro VIII observa-se que o eletrocardiograma, ao iniciar-se o tratamento, revelou-se normal em 7 casos $(29,1 \%)$, alterado em $17(\mathbf{7 0 , 8 \% )}$ e que, ao final do nesmo, estêve normal em $22(91,6 \%)$ e anormal em $2(8,3 \%)$. Cumpre assinalar que dentre os casos que apresentaram taquicardia sinusal incluimos apenas aquêles em que a frequêencia cardíaca foi significativamente elevada e nos quais outras causas capazes de determinar seu aparecimento pudessem ser afastadas, como, por exemplo, a febre. A baixa voltagem de QRS no plano frontal só foi considerada como alteração quando afastadas as causas extracardíacas que podem determinar 


\section{QUA-DRO I X}

RESULTADOS DE EXAMES RADIOLÓGICOS DO CORAÇÃO PRATICADOS ANTES E APÓS O TRATAMENTO EM 22 PACIENTES COM A FASE AGUDA DA DOENÇA DE CHAGAS, PARASITOLÓGICAMENTE COMPROVADA ATRAVÉS DO EXAME DIRETO, TRATADOS COM NITROFURANOS EM ESQUEMAS DE DURAÇÃO PROLONGADA

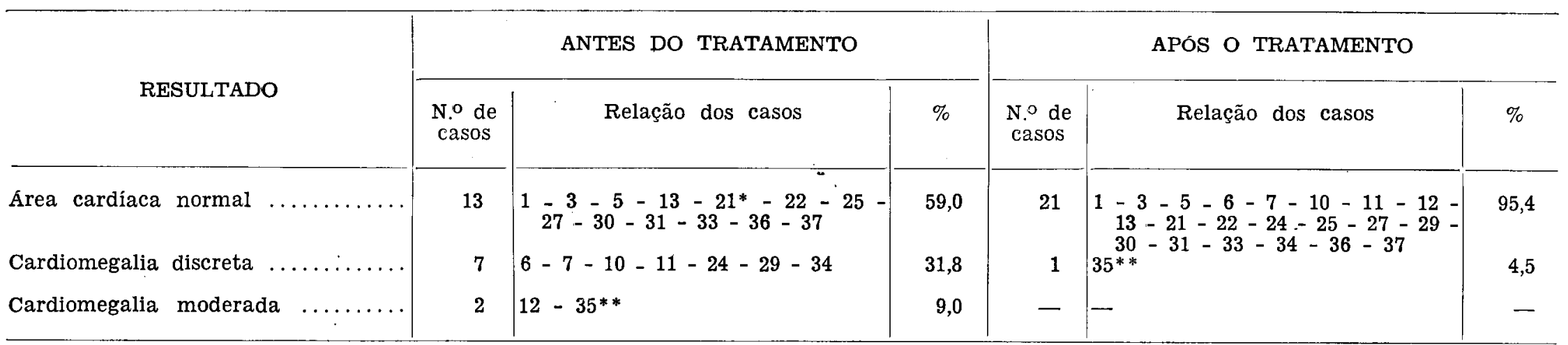

* Neste caso a área cardíaca mostrou-se moderadamente aumentada no $320^{\circ}$ dia de tratamento, normalizando-se 8 dias após, ainda durarte o tratamento.

* Paciente com anemia de células falciformes. 
seu aparecimento ou nos casos em que desapareceu à evolução. Pode-se notar que apenas nos casos 21,22 e 30 constituiram manifestaçōes isoladas; nos demais, estiveram associadas a outra ou outras alteraçōes.

O Quadro IX mostra que, antes do tratamento, a área cardíaca resultou normal em 13 pacientes $(59,0 \%)$ e aumentada em $9(40,9 \%)$ e que, após o tratamento, revelou-se normal em $21(95,4 \%)$ e discretamente aumentada em apenas um caso $(4,5 \%)$.

Com vistas a uma apreciação mais profunda dêsses resultados, em virtude das ponderações que fizemos ao tratarmos do valor dos referidos exames na avaliação da atividade medicamentosa, reunimos os casos, em número de 10 , nos quais conseguimos realizá-los seriadamente, em geral a intervalos semanais nos 2 primeiros meses e quinzenais em seguida (Quadro $\mathbf{X}$ ).

$A$ análise do Quadro $\mathbf{X}$ mostra que em 9 dos 10 pacientes houve evidências radiológicas e/ou eletrocardiográficas de comprometimento cardiaco, radiológicas em 6 (casos 6, 10, 12, 21, 34 e 35) e eletrocardiográficas em 7 (casos 5, 6, 12, 21, 22, 35 e $36)$; apenas o caso 13 teve sempre normais ambos os exames. Observa-se que a área cardíaca normalizou-se em 5 casos, no decurso do tratamento, entre o $4 .^{\circ}$ e o $43 .^{\circ}$ dias de uso da medicação ou, por outra, entre o $31 .^{\circ}$ e o $700^{\circ}$ dias de doença. No caso 21 a silhueta cardiaca, que era normal antes do tratamento, mostrou-se aumentada $n_{0} 32 .^{\circ}$ dia de tratamento (54. ${ }^{\circ}$ de doença), retornando à normalidade 8 dias após. Já as alterações eletrocardiográficas tardaram mais a desaparecer, tendo o traçado se normalizado durante o tratamento em um paciente (caso 6), no $14 .^{\circ}$ dia de tratamento ou $41 .^{\circ}$ dia de doença) e após o tratamento em 3 (casos 5, 12 e 21 , nos $33 .^{\circ}, 44 .^{\circ}$ e $40 .^{\circ}$ dias pós-terapêtica ou $115 .^{\circ} ; 116 .^{\circ}$ e $208 .^{\circ}$ dias de doença respectivamente); em 2 pacientes (casos 22 e 36) persistiu, como alteração, no periodo pós-terapêutico imediato, taquicardia sinusal importante e que desapareceu posteriormente, em periodo que não nos foi possível precisar. Nos casos 12, 21 e 22 apareceram, durante o tratamento, outras alterações, além das registradas anteriormente ao mesmo. Apenas o caso 35, que se refere a paciente com anemia de células falciformes, continuou com os exames radiológico e eletrocardiográfico alterados, assim mesmo, tendo ocorrido redução da área cardíaca durante o tratamento, cumprindo assinalar que, nesse período, foram feitas 9 transfusões de sangue de $300 \mathrm{ml}$ cada.

Efeitos colaterais. Acham-se relacionados no Quadro XI.

Hiporexia e emagrecimento foram observados em 12 dentre $13(92,3 \%)$ pacientes tratados com o derivado nitrofurfurilidínico ("Bayer" 2502), em 5 dentre $8(62,5 \%)$ medicados com levo-furaltadona e em 6 dentre $10(60,0 \%)$ que receberam nitrofurazona. Tais manifestações foram mais acentuadas com os dois primeiros medicamentos (nos quais a intensidare foi similar), que com o último e, geralmente guardaram relação direta com a posologia, tempo de administração e período etário. Em nenhum caso constituíram motivo para suspensão do tratamento. Regra geral, tiveram início na segunda ou terceira semanas de tratamento e se acentuaram, progressivamente, durante o mesmo. A redução do pêso corporal oscilou em tôrno de 10 a $20 \%$. Terminada a administração do medicamento, sempre ocorreu desaparecimento dos referidos sintomas, com ascenção gradativa da curva ponderal, registrando-se o pêso primitivo ao fim de 2 meses, aproximadamente. Orexigenos, como carnitina e ciproheptadina, foram administrados, concomitantemente, a alguns pacientes, não ocorrendo, entretanto, anulação da inapetência.

Polineuropatia periférica apareceu em 8 dentre $10(80,0 \%)$ casos tratados com nitrofurazona, em 4 dentre $8(50,0 \%)$ medicados com levo-furaltadona, em 3 dentre $9(33,3 \%)$ que usaram furazolidona e em apenas um dentre $13(7,6 \%)$ que receberam o derivado nitrofurfurilidinico ("Bayer 2502). Do tipo sensitivo-motora, principalmente sensitiva, e motora apenas nos casos mais graves, suas manifestações foram idênticas às da polineuropatia alcoólica. De localização bilateral e simétrica, atingiu mais os membros inferiores que os superiores, predominando nos segmentos distais. A intensidade dos sintomas foi maior no grupo de pacientes que recebeu nitrofurazona, algo menor no tratado com levo-furaltadona e escassa na paciente medicada com o derivado nitrofurfurilidínico, ocorrendo aqui, também, na grande maioria dos casos, relação direta 
EXAMES RADIOLÓGICOS DO CORAÇÃO E ELETROCARDIOGRAMAS PRATICADOS SERIADAMENTE, ANTES, DURANTE E APÓS O TRATAMENTO EM 10 PACIENTES COM A FASE AGUDA DA DOENCCA DE CHAGAS, PARASITOLOGICAMENTE COMPROVADA ATRAVÉS DO EXAME DIRETO, TRATADOS COM NITROFURANOS EM ESQUEMAS DE DURAÇÃO PROLONGADA

\begin{tabular}{|c|c|c|c|c|c|c|c|}
\hline \multirow{2}{*}{ Caso } & \multirow{2}{*}{$\begin{array}{l}\text { EXAME } \\
\text { n.o Período }\end{array}$} & \multicolumn{3}{|c|}{ RX-CORAÇÃO } & \multicolumn{3}{|c|}{ ELETROCARDIOGRAMA } \\
\hline & & $\begin{array}{l}\text { Antes do } \\
\text { tratamento }\end{array}$ & $\begin{array}{l}\text { Durante o } \\
\text { tratamento }\end{array}$ & $\begin{array}{l}\text { Após o } \\
\text { tratamento }\end{array}$ & $\begin{array}{l}\text { Antes do } \\
\text { tratamento }\end{array}$ & $\begin{array}{l}\text { Durante o } \\
\text { tratamento }\end{array}$ & $\begin{array}{l}\text { Após o } \\
\text { tratamento }\end{array}$ \\
\hline 5 & $\ldots \ldots \ldots \ldots$ & $\mathbf{N}$ & $\mathbf{N}$ & $\mathbf{N}$ & Alt. primária RV & Alt. primária RV & $\mathbf{N}\left(33 .^{\circ}\right.$ dia $)$ \\
\hline 6 & $\ldots \ldots$ & + & $\mathrm{N}\left(4 .^{\circ} \mathrm{dia}\right)$ & $\mathbf{N}$ & $\begin{array}{l}\text { Baixa volt. QRS } \\
\text { Alt. primária RV }\end{array}$ & $\mathbf{N}\left(14 .^{\circ}\right.$ dia $)$ & $\mathbf{N}$ \\
\hline 10 & $\ldots \ldots \ldots \ldots$ & + & $N\left(41 .^{\circ}\right.$ dia $)$ & $\mathrm{N}$ & $\mathrm{N}$ & $\mathbf{N}$ & $\mathbf{N}$ \\
\hline 12 & $\ldots \ldots \ldots$ & ++ & $N\left(43 .^{\circ}\right.$ dia $)$ & $\mathbf{N}$ & $\begin{array}{l}\text { Taq. sin. } \\
\text { Alt. primária } \mathrm{RV}\end{array}$ & $\begin{array}{l}\text { Acentuação taq. } \sin . \\
\text { Alt. primária RV } \\
\text { Sist. el. prolong. }\end{array}$ & N (44. ${ }^{\circ}$ dia $)$ \\
\hline 13 & $\ldots \ldots \ldots \ldots$ & $\mathbf{N}$ & $\mathbf{N}$ & $\mathrm{N}$ & $\mathbf{N}$ & $\mathbf{N}$ & $\mathbf{N}$ \\
\hline 21 & $\ldots \ldots \ldots \ldots$ & $\mathbf{N}$ & $\frac{++}{N}\left(40.0^{\circ}\right.$ dia $)$ & $\mathbf{N}$ & Baixa volt. QRS & $\begin{array}{l}\text { Taq. sin. } \\
\text { Alt. primária RV } \\
\text { Sístole el prolong. } \\
\text { Corrente lesão (V2) } \\
\text { SVE }\end{array}$ & N (40.0 dia) \\
\hline 22 & $\ldots \ldots \ldots \ldots$ & $\mathbf{N}$ & $\mathbf{N}$ & $\mathbf{N}$ & Taq. sin. & $\begin{array}{l}\text { Acentuação taq. sin. } \\
\text { FAV 1.0 grau rel. } \\
\text { Sist. el. prolong. }\end{array}$ & Taq. sin. (34..$^{\circ}$ dia $) *$ \\
\hline 34 & $\ldots \ldots \ldots \ldots$ & + & $\mathrm{N}\left(7 .^{\circ} \mathrm{dia}\right)$ & $\mathbf{N}$ & $\mathbf{N}$ & $\mathbf{N}$ & $\mathbf{N}$ \\
\hline 35 & $\ldots \ldots \ldots \ldots \ldots$ & $+t$ & $+\left(35 .^{\circ}\right.$ dia $)$ & + & SVE & SVE & $\operatorname{SVE}\left(200^{\circ} \mathrm{dia}\right)$ \\
\hline 36 & $\ldots \ldots \ldots \ldots$ & $\mathbf{N}$ & $\mathbf{N}$ & $\mathrm{N}$ & $\begin{array}{l}\text { Taq. sin. } \\
\text { BAV } 10^{\circ} \text { grau rel. } \\
\text { SVE }\end{array}$ & Taq. sin. (99. dia) & Taq. $\sin .\left(10^{\circ} \mathrm{dia}\right)^{*}$ \\
\hline
\end{tabular}

* Desapareceu posteriormente. 
entre a intensidade das manifestações, de um lado, e posologia e idade, de outro; com efeito, foram mais acentuadas no grupo de pacientes tratados com $30 \mathrm{mg} / \mathrm{kg}$ de pêso/dia e nos adultos ou adolescentes que nas crianças e, nestas, nas mais próximas da adolescência que da infância. A polineuropatia periférica constituiu motivo para suspensão do tratamento, dada a magnitude da sintomatologia, em 4 dos 8 pacientes que a apresentaram devido ao uso de nitrofurazona (casos 5, 20, 21 e 22), em 3 dos 4 em que apareceu durante o emprego de levo-furaltadona (casos 7, $10 \mathrm{e}$ 23) e em um dos 3 em que foi causada pela furazolidona (caso 12). Com a nitrofurazona as manifestaçōes de polineuropatia periférica apareceram entre o $10^{\circ}$ e o $45 .^{\circ}$ dias de tratamento $\left(24 .^{\circ}\right.$ dia, em média) e desapareceram entre o $90^{\circ}$ e 0 $3300^{\circ}$ dias após sua interrupção $\left(1000^{\circ}\right.$ dìa, em média). Com a levofuraltadona e com a furazolidona 0 início da sintomatologia se deu entre o $300^{\circ}$ e o $800^{\circ}$ dias de tratamento (45..$^{\circ}$ dia, em média) e seu desaparecimento entre o $25 .^{\circ}$ e $52 .^{\circ}$ dias $\left(400^{\circ} \mathrm{dia}\right.$, em média) após o mesmo. No único paciente (caso 25), dentre os medicados com - derivado nitrofurfurilidínico ("Bayer" 2502), em que ocorreu polineuropatia periférica, seu aparecimento se deu no 50. dia de tratamento, não mais sendo notada no $20 .^{\circ}$ dia após seu término. Em alguns casos continuou se agravando, mesmo tendo sido interrompida a administração do medicamentio. A remissão das manifestações foi gradativa, completando-se em todos os casos. Vitaminas B1, B6 e B12, administradas em doses generosas, profilática ou terapêuticamente, não preveniram o aparecimento da polineuropatia periférica e nem pareceram ter exercido influência sôbre sua evolução.

Em nenhum caso houve evidência de comprometimento dos pares cranianos.

Apresentaram náuseas e/ou vômitos 7 dentre $8(87,5 \%)$ pacientes medicados com levo-furaltadona, 3 dentre $10(30,0 \%)$ que receberam nitrofurazona e apenas um dentre $13(7,6 \%)$ tratados com o derivado $\mathrm{ni}$ trofurfurilidínico ("Bayer 2502). Quanto à intensidade, foi maior no grupo de pacientes que usou a levo-furaltadona, assim mesmo em grau moderado. Apareceram nos primeiros dias de tratamento, coincidindo com as doses mais altas de qualquer um dos nitrofuranos referidos (geralmente, $30 \mathrm{mg} / \mathrm{kg}$ de pêso/dia), em forma descontínua ou ocasional. Nem a freqüência e nem a intensidade dêsses sintomas constituíram motivo para interrupção do tratamento ou mesmo redução da posologia prèviamente programada. As vêzes foram administrados anti-eméticos, como dramamina, ciclizina e promazina, em doses comuns, com resultados favoráveis.

Insônia, de leve grau, foì referida por 3 dentre $8(37,5 \%)$ pacientes tratados com levo-furaltadona, 2 dentre $10(20,0 \%)$ medicados com nitrofurazona e um dentre $13(7,6 \%)$ que receberam o derivado nitrofurfurilidínico ("Bayer" 2502), todos na dose de $30 \mathrm{mg} / \mathrm{kg}$ de pêso/dia. A administração concomitante de benzodiazepínico, em dose habitual, anulou o referido sintoma.

Um só paciente (caso 22) apresentou crise convulsiva generalizada, tipo tônicoclônico, no 8. dia de tratamerto com nitrofurazona, na dose de $30 \mathrm{mg} / \mathrm{kg}$ de pêso/ dia. Não apresentava febre e nem quadro de meningoencefalite. $O$ episódio não se repetiu, apesar do paciente continuar recebendo o medicamento, na mesma dose, por mais 22 dias, sem terapêtica anticonvulsivante simultânea. Cumpre assinalar que, com um ano de idade, após queda de uma cadeira, o menor apresentou várias convulsōes durante alguns dias. O exame radiológico do crânio, praticado durante 0 tratamento com nitrofurazona e o eletroencefalograma, realizado 8 meses após, resultaram normais.

Quadro de depressão psíquica, transitório, caracterizado por apatia e tristeza, foi observado $n_{0}$ caso 3 , tratado com nitrofurazona, na dose de $30 \mathrm{mg} / \mathrm{kg}$ de pêso/ dia.

Quadro de disc:eta anemia hemolitica, laboratorialmente comprovada, foi observado no caso 21 , paciente de cĉr parda, 3 dias após o início do tratamento com nitrofurazona, na dose de $30 \mathrm{mg} / \mathrm{kg}$ de pêso/ dia. O medicamento foi suspenso. A ictericia regređiu gradativamente, não mais sendo notada 5 dias após sua instalação. Ressaltamos que, após a remissão da icterícia, o paciente continuou tomando nitrofurazona, por mais 10 dias, na mesma dose (30 $\mathrm{mg} / \mathrm{kg}$ de pêso/dia) e, posteriormente, levo-furaltadona (dose de $30 \mathrm{mg} / \mathrm{kg}$ de pêso/dia/16 dias, seguida da dose de 10 
QUADRO XI

EFEITOS COLATERAIS OBSERVADOS EM 37 PACIENTES COM A FASE AGUDA DA DOENÇA DE CHAGAS, PARASITOLOGICAMENTE COMPROVADA ATRAVÉS DO EXAME DIRETO, TRATADOS COM NITROFURANOS EM ESQUEMAS DE DURAÇÃO PROLONGADA

\begin{tabular}{|c|c|c|c|c|c|}
\hline Efeitos colaterais & $\begin{array}{l}\text { N.o de } \\
\text { casos }\end{array}$ & Medicamento & $\begin{array}{c}\text { Total de } \\
\text { casos } \\
\text { tratados }\end{array}$ & $\%$ & Relação dos casos \\
\hline $\begin{array}{l}\text { HIPOREXIA } \\
\underset{E}{E} \\
\text { EMAGRECIMENTO }\end{array}$ & $\begin{array}{r}12 \\
5 \\
6\end{array}$ & $\begin{array}{l}\text { Derivado nitrofurfurilidínico } \\
\text { Levo-furaltadona } \\
\text { Nitrofurazona }\end{array}$ & $\begin{array}{r}13 \\
8 \\
10\end{array}$ & $\begin{array}{l}92,3 \\
62,5 \\
60,0\end{array}$ & $\begin{array}{l}25-26-27-28-30-31-32-33-34-35-36-37 \\
7-8-9-10-23 \\
1-2-3-5-21-22\end{array}$ \\
\hline $\begin{array}{l}\text { POLINEUROPATIA } \\
\text { PERIFERICA }\end{array}$ & $\begin{array}{l}8 \\
4 \\
3 \\
1\end{array}$ & $\begin{array}{l}\text { Nitrofurazona } \\
\text { Levo-furaltadona } \\
\text { Furazolidona } \\
\text { Derivado nitrofurfurilidínico }\end{array}$ & $\begin{array}{r}10 \\
8 \\
9 \\
13\end{array}$ & $\begin{array}{r}80,0 \\
50,0 \\
33,3 \\
7,6\end{array}$ & $\begin{array}{l}1-2-3-5-6-20-21-22 \\
7-8-10-23 \\
12-13-16 \\
25\end{array}$ \\
\hline $\begin{array}{l}\text { NÁUSEAS } \\
\text { e/ou } \\
\text { VOMMITOS }\end{array}$ & $\begin{array}{l}7 \\
3 \\
1\end{array}$ & $\begin{array}{l}\text { Levo-furaltadona } \\
\text { Nitrofurazona } \\
\text { Derivado nitrofurfurilidínico }\end{array}$ & $\begin{array}{r}8 \\
10 \\
13\end{array}$ & $\begin{array}{r}87,5 \\
30,0 \\
7,6\end{array}$ & $\begin{array}{l}7-8-9-10-20-21-23 \\
20-21-22 \\
34\end{array}$ \\
\hline INSONIA & $\begin{array}{l}3 \\
2 \\
1\end{array}$ & $\begin{array}{l}\text { Levo-furaltadona } \\
\text { Nitrofurazona } \\
\text { Derivado nitrofurfurilidinico }\end{array}$ & $\begin{array}{r}8 \\
10 \\
13\end{array}$ & $\begin{array}{r}37,5 \\
20,0 \\
7,6\end{array}$ & $\begin{array}{l}7-8-23 \\
1-2 \\
25\end{array}$ \\
\hline CONVULSÃO & 1 & Nitrofurazona & 10 & 10,0 & 22 \\
\hline DEPRESSÃO PSIQUICA & 1 & Nitrofurazona & 10 & 10,0 & 3 \\
\hline ANEMIA HEMOLITICA & 1 & Nitrofurazona & 10 & 10,0 & 21 \\
\hline ALERGIA CUTÂNEA & 1 & Nitrofurazona & 10 & 10,0 & 4 \\
\hline DOR ARTICULAR & 1 & Nitrofurazona & 10 & 10,0 & 6 \\
\hline LEUCOPENIA & 1 & Levo-furaltadona & 8 & 12,5 & 8 \\
\hline
\end{tabular}


$\mathrm{mg} / \mathrm{kg}$ de pêso/dia/97 dias), sem que 0 quadro de repetisse.

Alergia cutânea se apresentou no caso 4 , ao final do tratamento com nitrofurazona, desaparecendo poucos dias após o uso do medicamento.

Dor articular, de pequena a moderada intensidade, não acompanhada de sinais flogisticos, localizada nos tornozelos, joeIhos, metacarpofalangeanas e metarsofalangeanas, foi referida por um paciente (caso 6), ao cabo da segunda semana de tratamento com nitrofurazona; durou apenas 5 dias, cedenđo espontâneamente.

Leucopenia de 3.400 elementos $/ \mathrm{mm} 3$ foi observada apenas em um paciente (caso 8), ao final do tratamento com levo-furaltadona. Em nenhum caso ocorreu alteração tóxica para o lado da série vermelha; pelo contrário, o que observamos foi a correção de anemia ferrípriva, presente em muitos casos ao ser iniciado o tratamento, cumprindo salientar que os pacientes receberam medicação férrica.

Em nenhum caso houve evidências laboratoriais de comprometimentc renal ou hepático.

Não houve ocorrência de óbito em nossa casuística.

\section{DISCUSSÃO}

A fase aguda da doença de Chagas presta-se bem para avaliação dos efeitos terapêuticos de um medicamento, principalmente pela facilidade com que se pode comprovar a parasitemia, ao contrário da fase crônica. Por outro lado, deve ser salientado que uma judiciosa interpretação dos resultados implica na seriação dos exames de contrôle por tempo razoàvelmente longo, se forem resultando negativos, para que se decida sôbre uma ação supressiva ou curativa do medicamento. O Quadro XII constitui um bom exemplo disso; se tivéssemos interrompido a observação da paciente decorridos $3 \frac{1}{2}$ meses após o tratamento, poderíamos concluir, intempestiva e errôneamente, pela cura, pois um número significativo de xenodiagnóstico e de reações de Guerreiro e Machado resultou negativo; entratanto, posteriormente, ambos os exames tornaramse positivos.

Os resultados obtidos demonstram que os nitrofuranos empregados, principalmente a nitrofurazona e o derivado nitrofurfu- rilidínico ("Bayer" 2502), à semelhança do que foi observado en infecções experimentais, têm ação na infecção chagásica aguda humana, exercendo manifesta diminuição da parasitemia, avaliada através de xenodiagnósticos, e abreviando o tempo de duração de certas manifestações clínicas.

O fato de não ter ocorriclo renhum óbito em nosso material, sabendo-se que o índice de mortaiidade na fase aguda gira $\mathrm{rm}$ tôrno de 3 a $5 \%$, poderia ser tomado indiretamente e com as devidas reservas - como evidência de uma ação protetora dos medicamentos ensaiados.

Uma estreita concordância entre os resultados do xenodiagnóstico e da reação de Guerreiro e Machado foi notada. Com efeito, pràticamente são superponíveis as representações esquemáticas apresentadas nos Gráficos I e II, ressalvado o fato, co- mo é óbvio, de que a obtenção de reações negativas deve ser posterior à de xenodiagnósticos negativos, tendo em vista o prazo necessário para esgotamento de anticorpos.

Apenas os casos 4, 9, 24 e 29 apresentaram, após o tratamento, xenodiagnósticos positivos e reações de Guerreiro e Machado negativas; nos demais, exceto o caso 2, no oual não foi feito contrôle sorológico, houve integral concordância de resultados entre ambos os exames. Para explicar o comportamento da reação naqueles 4 casos podem ser citados fatôres como tempo de doença, incompetência imunológica e índice de sensibilidade da reação.

Fato interessante a ser assinalado é que, em 10 casos crônicos, todos com xenodiagnósticos positivos, tratados com "Bayer" 2502, durante 120 dias, Schenone \& col. (41) observaram persistência de reações sorológicas positivas (reações de Guerreiro e Machado e de hemaglutinação), em contraste com xenodiagnósticos negativos, ambos os exames tendo sido realizados mensalmente durante os 10 primeiros meses após o início do ensaio terapêutico $e$, em seguida, no $13 .^{\circ}$ mês. Concluíram os Autores que a sorologia não constituiria um critério adequado para avaliar a eficácia de um tratamento na infecçāo chagásica crônica e que a persistência de reações sorológicas positivas, na ausência de tripanosomas circulantes, faz supor que se trata de situação similar ao que ocorre na sífilis e em outras treponematoses crônicas, nas quais persiste a positividade sorológi- 
QUADRO XII

ILUSTRAÇÃO DA NECESSIDADE DE SERIAÇÃO DE EXAMES DE CONTRÔLE DE ATIVIDADE TERAPÊUTICA POR TEMPO RAZOAVELMENTE LONGO

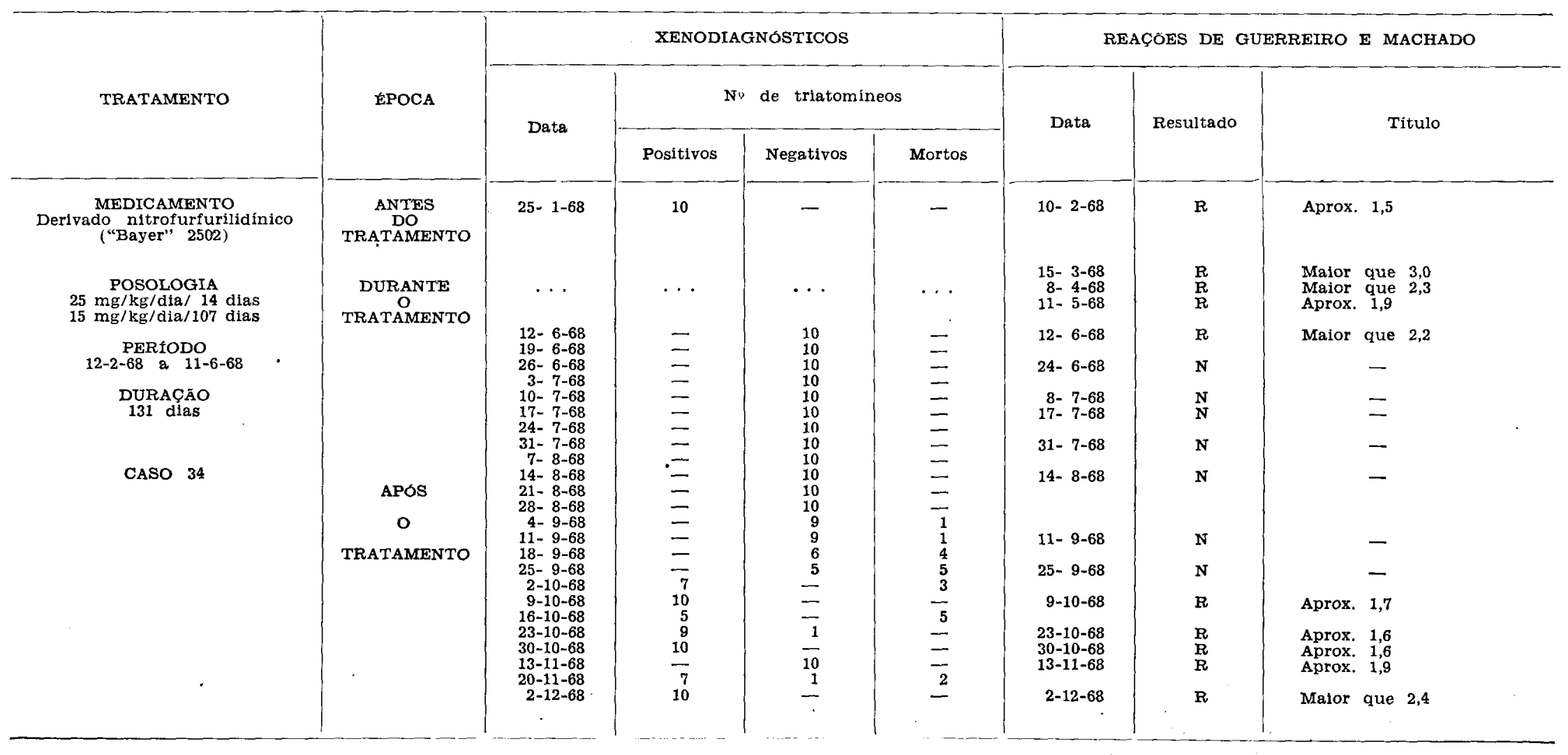

$\mathbf{R}$ - reagente

N - negativo 
RELAÇÃO DOS CASOS COM XENODIAGNÓSTICOS E REAÇóES DE GUERREIRO E MACHADO PERSISTENTEMENTE NEGATIVOS APÓS O TRATAMENTO, EM CONTRÔLE NEGATIVO A LONGO PRAZO

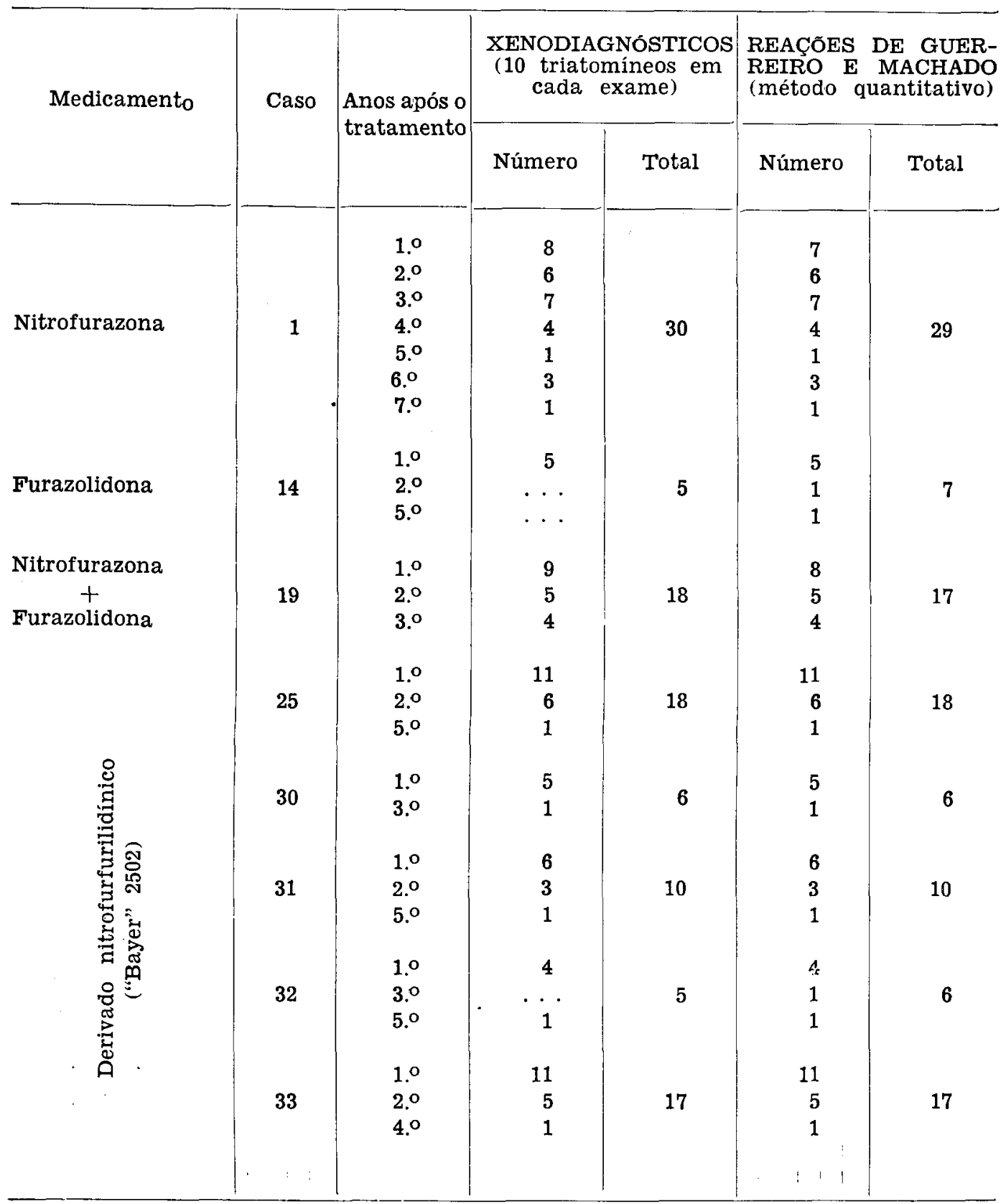


ca, apesar de um tratamento considerado suficiente.

$\mathrm{Na}$ maioria dos nossos pacientes pôde ser constatado um efeito supressivo, bastante expressivo no caso 5 , pela maneira com que foi feito o contrôle. Dos 8 pacientes que, após o tratamento, sempre apresentaram xenodiagnósticos e reações de Guerreiro e Machado negativos (Quadro XIII), um foi tratado com nitrofurazona (caso 1), um com furazolidona (caso 14), um com nitrofurazona associada à furazolidona (caso 19) e 5 com o derivado nitrofurfurilidínico "Bayer" 2502 (casos 25, 30, assunto encerra, considerar como curado um caso agudo que apresente, após o tratamento, xenodiagnósticos e reações de Guerreiro e Machado negativos durante um ano, quando seriada e reiteradamente praticados. É que, dentro dêsse prazo, em casos deixados evoluir naturalmente; o indice de sensibilidade do xenodiagnóstico ainda é alto e o da reação de Guerreiro e Machado atinge seu máximo, isto é, $98,6 \%$, sęgundo Freitas (25).

o eletrocardiograma e o exame radiológico do coração nāo constituíram bons

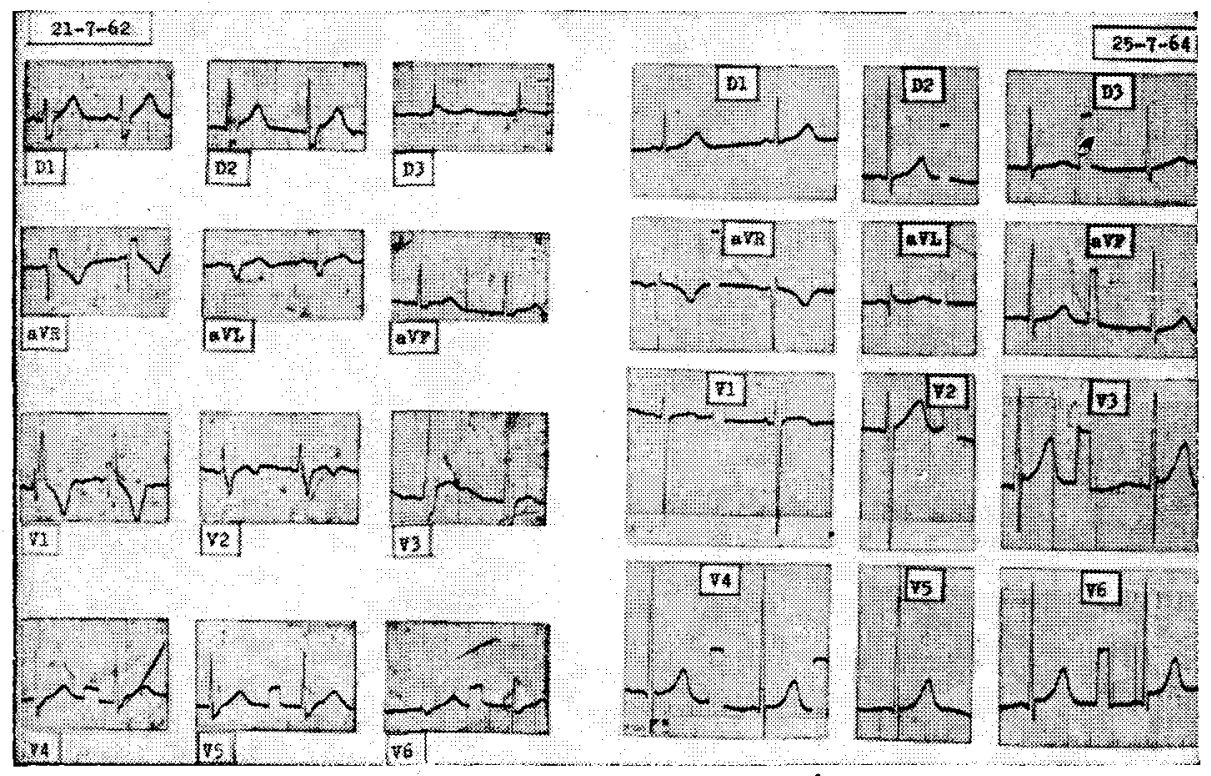

Figura I - Caso 19. O eletrocardiograma praticado durante a fase aguda da doença de Chagas (21-7-62) revela bloqueio completo do ramo direito do reixe de Hiss e o realizado em 25-7-64 se mostra normal.

31. 32 e 33). Estariam, êstes pacientes, curados da infecção? Parece-ros significativo, para responder afirmativamente a esta indagação, o fato de que, ao lado do xenodiagnóstico negativo está a reação de Guerreiro e Machado também negativa, ambos os exames tendo sido realizados reiteradas vêzes e por longo tempo, na maioria dos casos. Com a experiência adquirida através de várias tentativas de tratamento específico e através do estudo de casos agudos deixados evoluir naturalmente, julgamos cabivel, ainda que com certas ressalvas, pelo aspecto de novidade que o parâmetros para avaliação dos efeitos terapêuticos, uma vez que o desaparecimento das alterações registradas se der em tempo pràticamente superponível ao de casos não tratados (35). Merece referência, entretanto, o desaparecimento do bloqueio completo do ramo direito observado no caso 19 (Fjg. 1), um dos pacientes que poderiam ser considerados como curados, em função do satisfatório contrôle parasitosorológico a que foi submetido. Cumpre ressaltar que na casuística de Laranja \& col. (27) os dois únicos casos que apresentaram o referido distúrbio faleceram. 
Os efeitos colaterais observados foram idênticos aos referidos na literatura (bibliografia in Marra (30). A freoüência e a intensidade dos mesmos obrigam a uma continua vigilância do paciente, podendo motivar a interrupção do tratamento ou a redução da dose do medicamento. A não recorrência de hemólise no caso 21 , apesar do paciente ter continuado o uso de nitrofurazona, pode ser explicada em função de que a anemia hemolitica medicamentosa é auto-limitante; baseado neste fato e em que a recuperação do quadro se processa apesar da continuada administração do medicamento, Robertson (38) considerou razoável o emprêgo de nitrofurazona em casos refratários de doença do sono, mesmo na presença de estigma hemolítico. A administração de nitrofurazona e de levo-furaltadona ciclicamente, isto é, com intervalos de interrupção, não evitou o aparecimento de manifestações tóxicas e nem reduziu a intensidade das mesmas, nos poucos pacientes em que essa medida foi adotada (casos 7, 20 e 22).

Lamentàvelmente os compostos mais ativos (a nitrofurazona e o derivado nitrofurfurilidinico "Bayer" 2502) foram os que mais freqüente $e$ intensamente ocasionaram o aparecimento de manifestações tóxicas; tendo em conta, porém, que, em geral, instalam-se gradativamente, guardam relação direta com a posologia e são reversíveis, o emprêgo dos mesmos pode ser feito, desde que sob vigilância médica. Cumpre ressaltar, com respeito à nitrofurazona, que seus fabricantes (Eaton Laboratories), dados os efeitos colaterais, não mais se interessaram por novas investigaçōes com a mesma; opuseram-se, inclusive, a elas, ao mesmo tempo em que colocaram à nossa disposição outros dos compostos nitrofurânicos ensaiados.

\section{CONCLUSŌES}

Concluem os Autores, baseados nos resultados da presente investigação, que:

1 - Certos composto nitrofurânicos, especialmente a nitrofurazona e o derivado nitrofurfurilidinico ("Bayer" 2502), administrados em esquemas de duração prolongada, são ativos contra o $T$. cruzi na infecção aguda humana.

2 - Exercendo pelo menos atividade supressiva, quando não curativa, têm seu emprêgo altamente justificado no período inicial da infecção, desde quie sob vigilância médica, tendo em vista a ocorrência de efeitos colaterais. Certamente, apenas o contrôle da fase aguda, com redução do indice de mortalidade, e a baixa da parasitemia, condicionando a instalação de uma fase crônica protraída, já representam um significativo avanço no campo do tratamento específico da doença de Chagas, encorajando o prosseguimento das pesquisas, na busca de procutos menos tóxicos e mais ativos.

3 - Contando-se, atualmente, com o derivado nitrofurfurilidínico ("Bayer 2502), seu emprêgo é indicado na fase aguda, durante 90 dias ou mais, na dependência da tolerância e da evolução do caso, na dose de $25 \mathrm{mg} / \mathrm{kg}$ de pêso corporal/dia durante os primeiros 15 dias e, em seguida, na dose de $15 \mathrm{mg} / \mathrm{kg}$ de pêso/dia.

4 - Merece ser salientado que muita cautela deve-se ter na avaliação dos efeitos terapêuticos, parecendo ser significativa a obtenção de xenodiagnósticos e de reações de Guerreiro e Machado negativos durante um ano após o tratamento, quando seriada e reiteradamente praticados.

\section{SUMMARY}

The authors report on their experience with the nitrofuranes among 37 patients with acute Chagas' disease ireated according to schemes of long acting action. All patients had a direct positive parasitologic test for Chagas'disease.

The therapeutic response was based, mainly, on the xenodiagnostic and the Guerreiro-Machado test, which were taken as often as possible or whenever it was felt necessary, no matter what the result of the panasitologic test could be.

The results showed that the nitrofuranes, especially the nitrofurazone and the nitrofurfurylidene derivative "Bayer" 2502, are active agents against the T. cruzi, as seen through the manifest diminuition of blood parasites - by 
means of the xenodiagnostic test, the Guerreiro-Machado test which becomes negative, and also through the shortening of the clinical manifestations.

$A$ close relationship between ine results of the xenodiagnostic test and the Guerreiro-Machado test after treatment could be noted.

In most patients a supressive response could be observed, while in eight patients there was an apparent curative effect.

They emphasize the need to evaluate the therapeutic results during treatment, the necessity of keeping the patients under observation, for the side effects are common.

The authors finally concludie that the nitrofurfurylidene derivative "Bayer" 2502 shoud be given to patients with acute Chagas' disease.

\section{BIBLIOGRAFIA}

1 - AMATo, V., Neto - Contribuição ao conhecimento da forma aguda da doença de Chagas. São Paulo. Tip. Edanee. 1958. 332 p. Tese, Fac. Med. Univ. São Paulo.

2 - ANDRADE, Z. A. \& BRENER, Z. Ação da nitrofurazona (5-nitro-2furaldeído - semicarbazona) sôbre as formas intracelulares do Trypanoso$m a$ cruzi na doença de Chagas experimental. Rev. Inst. Med. Trop. São Paulo, 11: 222-228, 1969.

3 - BOCCA TOURRES, C. L. - La enfermedad de Chagas en período agudo y su tratamiento con el Bay 2502. Bol. Chile. Parasit., 24: 24-27, 1969.

4 - BOOK M.; GONNERT, R, \& HABERKORNER, A. - Studies with Bay 2502 on animals. Bol. Chile. Parasit., 24: 13-19, 1969.

5 - BRENER Z. - Contribuicão ao estudo da terapêutica experimental da doença de Chagas. Belo Horizonte, 1961. 79 p. Tese, Fac. Odont. Farm. Univ. Minas Gerais.

6 - BRENER, Z. - Atividade terapêutica do 5-nitro-furaldeído - semicarbazona (nitrofurazona) em esquemas de duração prolongada na infecção experimental do camundongo pelo Trypanosoma cruzi. Rev. Inst. Med. Trop. São Paulo, 3: 43-49, 1961.

7 - BRENER, $\mathrm{Z}$. - A atividade terapêutica da furaltadone, furazolidone $\mathrm{e}$ furadantina na infecção experimental do camundongo pelo "Trypanosoma cruzi". O Hcspital, 60: 947951, 1961.

8 - BRENER, Z., TAFURI, W. L. \& ALMEIDA MARIA, T. - An electron microscope study of Trypanosoma cruzi intracelular forms in mice treated with an active nitrofuran compound. Rev. Inst. Med. Trop. São Paulo, 11: 245-249, 1969.
9 - BUSTOS, A. G., SOSA, L. E. V.; CONSTANZO, S.,; WYBERT, L. A.; DE LUCIA, A. \& CARRIZO, F. A. Evolución clínica y de laboratório en niños adolescentes con infección chagásica crónica tratados con Bay 2502 y con placebo. Bol. Chile. Parasit., 24: 63-65, 1969.

10 - CANCADO, J. R.; MARRA, U. D. \& BRENER, $Z$. - Ensaio terapêutico clínico com a 5-nitro-2-furaldeído semicarbazona (nitrofurazona) na forma crônica da doença de Chagas. Rev. Inst. Med. trop. São Paulo, 6: 12-16, 1964 .

11 - CANCADO, J. R.; MARRA, U. D.; LOPES. M., MOURÄO. O.; FARIA, C. A. F.; ALVARES. J. M' \& SALGADO, A. de A. - Toxicidad y valor terapéutico del Bay 2502 en al enfermedad de Chagas crónica en tres esquemas posológicos. Bol. Chile. Parasit., 24: 28-32, 1969.

12 - CERISOLA, J. A. - Evclución serológica de pacientes con enfermedad de Chagas aguda tratados con Bay 2502. Bol. Chile. Parasit., 24: 54-59, 1969.

13 - CICHERO, J. A.; SEGURA, E. \& QUATROCHI, J. C. - Evolución clínico-parasitológica y tolerancia a la droga de 33 niños con infección chagásica crónica tratados con Bay 2502. Bol. Chile. Parasit., 24: 59-62, 1969.

14 - COSTA, R. de \& CORRADO, A. P. - Atividade tripanosomicida do 5nitro-2-furaldeído-2 (2-hidroxi-etil) - semicarbazona (Furadroxil) na moléstia de Chagas experimental. Rev. Inst. Med. trop. São Pualo, 5: 243-248, 1963.

15 - COURA, J. R.; FERREIRA, L. F. \& SILVA, J. R. da - Experiências com a nitrofurazona na fase crônica da doença de Chagas. Rev. Goiana Med. 9 (supl.) : 99-107, 1963. 
16 - DIAS, E. - Informações acêrca de 300 casos de doença de Chagas com periodo inicial conhecido, fichados no Centro de Estudos de Bambuí. O Hospital, 47: 647-653, 1955.

17 - EJDEN, J. - Efecto del Bay 2502 en adultos asintomáticos con infección chagásica crónica. Bol. Chile. Parasit., 24: 99-100, 1969.

18 - FERNÁNDEZ. J. J .; CEDILLOS, R A. \& GODOY, G. A. - Tratamiento de la enfermedad de Chagas aguda con Bay 2502. Bol. Chile. Parasit., 24: $51-53,1969$

19 - FERREIRA, H. de O. - Forma aguda da doenca de Chagas tratada pela nitrofurazona. Rev. Inst. Med. trop. São Paulo, 3: 287-289, 1961.

20 - FERREIRA, H. de 0 . - Fase aguda da doença de Chagas. O Hospital, 61: 307-311, 1962 .

21 - FERREIRA, H. de O. - Experiências com nitrofuranos na terapêtica da doença de Chagas. O Hospital, 65: 793-802, 1964.

22 - FERREIRA, H. de O. - Tratamento da doença de Chagas (fase aguda) com Bayer 2502. Rev. Inst. Med. trop. São Paulo, 9: 343-345, 1967.

23 - FERREIRA, H. de O. - Comparación de la tolerancia medicamentosa de la nitrofurazona, la levofuraltadona (NF-602) y el Bay 2502. Bol. Chile. Parasit., 24: 101-103, 1969.

24 - FERREIRA, H. de O.; PRATA, A. \& RASSI, A. - Administração prolongada de nitrofurazona no tratamento da doença de Chagas aguda. O Hospital, 63: 1391-1396, 1963.

25 - FREITAS, J. L. P. de - Diagnóstico de laboratório da moléstia de Chagas. Bol. Of. Sanit. Panamer., 51: 429-438, 1961 .

26 - FREITAS, J. L. P. de \& ALMEIDA, J. O. de - Nova técnica de fixação do complemento para moléstia de Chagas (Reação quantitativa com antígeno gelificado de culturas de Trypanosoma cruzi) . O Hospital, 35: 787-800, 1940.

27 - LARANJA, F. S.; DIAS, E.; NOBREGA, G. \& MIRANDA, A. - Chagas' disease; a clinical epidemiologic, and pathologic study. Circulation, 14: 1035-1060, 1956.

28 - LUGONES, H. S.; PERALTA, F.; CANAL FEIJÓO, D. \& MARTELEUR, A. E. F. de - Evolución de la sintomatologia clinica y la función hepática en la enfermedad de Chagas aguda tratada con Bay 2502. Bol. Chile. Parasit., 24: 19-24, 1969.
29 - MAEKELT, G. A. - Evaluación clínica e serológica de la droga Bay 2502 en pacientes con infección chagásica crónica. Bol. Chile. Parasit., 24: 95-96, 1969 .

30 - MARRA, U. D. - Ensaio terapêutico clínico com a nitrofurazona e a levofuraltadona na forma crônica da doença de Chagas. Belo Horizonte, Imprensa Univ. Minas Gerais, 1965. 143 p. Tese. Fac. Medicina Univ. Minas Gerais

31 - PACKCHANIAN, A - Chemotherapy of experimental Chagas'disease with nitrofuran compounds. Antib. \& Chemo., 7: 12-23, 1957.

32 - PINTO, L. W.; FOURNIOL, D. \& Di SANTO, L. - Experiência terapêutica com o Bayer 2502 em um grupo homogêneo de pacientes adultos com moléstia de Chagas crônica. Fôlha méd., 60: 309-326, 1970.

33 - PRATA A. \& FERREIRA, H. - Dois casos de doença de Chagas aguda aparentemente curados pela nitrofurazona. Gaz. méd. Bahia, 69: 2529,1969 .

34 - RASSI, A.; BORGES, C.; REZENDE, J. M. de: CARNEIRO, O.; SALUM, J.; RIBEIRO I. B. \& PAULA, O. H. de - Fase aguda da doença de Chagas. Aspectos clínicos observados em 18 casos. Rev. Goiana Med., 4: 161189,1958 .

35 - RASSI, A. \& CARNEIRO, O. - Alterações circulatórias na fase aguda da doença de Chagas. In: CANÇADO, J. R., ed. - Doença de Chagas. Belo Horioznte. Imprensa Of. Est. Minas Gerais, 1968, p. 374-392.

36 - RASSI, A.; REZENDE, J. M. de \& DOLES, J. - Caso de doença de Chagas observado desde o período inicial da infecção, com aparecimento precoce de megaesôfago e megacolo. Rev. Soc. Bras. Med. Trop., 2: 303-315, 1968 .

37 - REBOSOLÁN, J . B - - Sensibilidad de los métodos de diagnóstico parasitológico en pacientes con enfermedad de Chagas aguda tratados con Bay 2502. Bol. Chile. Parasit., 24: 49$50,1969$.

38 -ROBERTSON, D. H. H. - Nitrofurazone-induced haemoiytic anaemia in a refractory case of Trypanosoma rhodesiense sleeping sickness: the haemolytic trait and self-limiting haemolytic anaemia. Ann. Trop. Med. Parasit., 55: 49-63, 1961. 
39 - ROMERO, G. - Investigación terapéutica del Bay 2502 en adultos jóvenes con infección chagásica crónca. Bol. Chile. Parasit., 24: 97-99, 1969.

40 - RUBIO, M. \& DONOSO, F. - Enfermedad deChagas en niños y tratamiento con Bay 2502. Bol. Chile. Parasit., 24: 43-48, 1969 .

41 - SCHENONE, H.; CO N C H A, L. ; ARANDA, R.; ROJAS, A. \& ALFARO, E. - Experiếncia terapéutica con el Bay 2502 en la infección chagásica crónica del adulto. Importancia del uso adecuado del xenodiagnóstico. Bol. Chile. Parasit., 24: 66-69, 1969.
42 - SENECA, H.; PEER, P. M. \& REGAN, J. W. - Chemotherapy of experimental Trypanosoma cruzi infection in mice with L-furaltadone. Exper. Parasitol., 15: 479-484, 1964.

43 - VALECILLOS, V., R. I. - Investigación terapéutica del Bay 2502 en pacientes con miocardiopatía chagásica crónica. Observaciones sobre tolerancia clinica y de los parenquimas. Bol. Chile. Parasit., 24: 96-97, 1969.

44 - WESTERN, K. A.; SCHULTZ, M. G.; FARRAR, W. E. \& KAGAN, I. G. Laboratory acquired Chagas'disease treated with Bay 2502. Bol. Chile. Parasit., 24: 94, 1969. 